\title{
GENTSE HANDSCHRIFTEN MET KEUKEN- RECEPTEN VAN DE 17DE EN 18DE EEUW
}

\author{
Daniel Lievois
}

\section{Inleiding}

In het Nederlandse taalgebied bleven er maar een goed tiental handgeschreven kook- of receptenboeken van vóór 1800 bewaard. Gent is onder dit opzicht uitzonderlijk rijk bedeeld, want de oudste drie manuscripten worden er bewaard. Het oudst bekende kookboek bevindt zich in de bibliotheek van de Gentse universiteit en bevat 62 keukenrecepten uit de 15de eeuw. (1) Een handschrift in de bibliotheek van de Koninklijke Academie voor Nederlandse Taal- en Letterkunde omvat vier manuscripten die in één band werden samengebracht; ze dateren wellicht van het laatste kwart van de 15 de eeuw tot het begin van de 16 de eeuw. Behalve 92 recepten uit de 15 de eeuw, bevat het nog 332 jongere recepten waarvan de meeste keukenrecepten een Brabantse herkomst verraden. (2) In dezelfde bibliotheek bevindt zich nog handschrift uit het eerste kwart van de 16de eeuw; de 267 recepten werden overgenomen uit het Frans en het Duits, vermoedelijk door een Vlaming. (3) Andere manuscripten met recepten dateren ten vroegste van het einde van de 16 de eeuw; vier ervan behoorden toe aan religieuze communauteiten. Een niet gepubliceerd 17de-eeuws Brabants kookboek werd in 2010 overgedragen aan de Erfgoedbibliotheek Hendrik Conscience in Antwerpen. Het telt 56 pagina's in quarto en behoorde tot de nalatenschap van volkskundig en culinair historicus W. L. Braekman (1931-2006). (4)

Aan dit lijstje kunnen er nu twee Gentse handschriften worden toegevoegd die respectievelijk omstreeks 1603 en in de tweede helft van de 18de eeuw te situeren vallen. In deze bijdrage wordt eerst het oudste behandeld en vervolgens het jongere manuscript dat uitsluitend aan bakkerijproducten is gewijd. Uiteraard zijn de gedrukte kookboeken ook van het grootste belang, maar die vallen buiten het bestek van deze publicatie. (5)

\section{Maten en gewichten}

Het Gents pond werd door Faipoult bepaald op 0,4333 kg. (6) Het werd onder meer ingedeeld in 16 ons, in 32 lood en in 320 engelse. Dus : 1 ons is $27 \mathrm{~g}$, 1 lood $13 \frac{1}{2}$ g en 1 engelse 1,35 g. Voor boter woog het pond wellicht iets minder. In Brugge stond het gewone pond voor 0,4639 $\mathrm{kg}$ en het boterpond voor $0,436449 \mathrm{~kg}$; een verschil dus zowat $5 \%$. Er moet worden toegegeven dat men voor Gent geen specifiek boterpond kent (7), maar als dezelfde verhouding van Brugge ook in Gent gold, zou het Gentse boterpond 0,4118 kg hebben gewogen. Een vierde boter woog dan zowat $0,10295 \mathrm{~kg}$, terwijl het anders $0,1083 \mathrm{~kg}$ zou zijn. We kunnen dus met een gerust geweten zeggen we dat een vierde boter $100 \mathrm{~g}$ woog. Bij de maten van vloeistoffen stond 
1 stoop voor 2 potten of 4 pinten, dit wil zeggen dat 1 pint gelijk was aan 0,5766 liter (8), 1 pot aan 1,15 I en 1 stoop aan 2,3 I.

Uitzonderlijk komt in het bakkerijhandschrift een "maetje" voor. Een maatje was één zesde van een pint of dus 9,61 cl. Het is dus aanvaardbaar om voor $10 \mathrm{cl}$ te opteren en dus voor een dubbel maatje van $20 \mathrm{cl}$. In het recept van "Anys bosschuyt" - anijsbiscuit komt als maat voor eieren een gewicht voor, namelijk "een alf pond en een alf vierde eyers" of dus 0,625 pond of nog 0,27 $\mathrm{kg}$. Dit wijst erop dat de gehele eieren werden gewogen. Nu wegen eieren gemiddeld 58 gram voor een inhoud van $53 \mathrm{~cm}^{3}$, waarvan $10 \%$ voor de schaal. (9) Dit geldt althans voor de actuele eieren in Australië. Wellicht was dit in de 18 de eeuw iets minder. Dit wijst er dus op dat "een alf pond en een alf vierde eyers" zowat gelijkstaat met een viertal eieren.

\section{Het receptenboekje van Pieter de Seclyn - 1603}

Dit onbekende keukenmanuscript bevindt zich in het Gentse Rijksarchief in het Familiefonds. (10) Het boekje met 69 recepten is geen kookboek omdat het helemaal geen volledig overzicht geeft van wat men in de keuken kon bereiden. Het vertoont een langwerpig formaat van $10 \mathrm{bij} 31,5 \mathrm{~cm}$ en is nagenoeg 1,5 cm dik. De katernen werden verzameld onder een hergebruikt tekstfragment op perkament. De auteur noteerde de keukenrecepten in het eerste deel, namelijk op de folio's 1 tot en met 9, daarna viel de foliëring weg; van dezelfde hand volgen helemaal achteraan geneeskundige recepten voor dieren en enkele dito recepten voor mensen, alsmede een recept om inkt te vervaardigen. Het vlotte handschrift van de auteur is duidelijk te herkennen in vergelijking met dat van andere personen die het boekje later gebruikten om er huishoudelijke uitgaven en inkomsten in te noteren tot 1645. Diverse verwijzingen naar kinderen en andere familieleden verraden de identiteit van de oorspronkelijke auteur wiens naam nergens wordt vermeld. Zijn zoon Joos begon school te lopen bij meester Gillis op 13 maart 1606. Op 14 april 1609 stelde zijn vader hem voor aan de prefect van de patres, wellicht de jezuieten, waar hij op 27 april begon te studeren. Andere schoolgaande zonen waren Franchois en Jan. Dochter Janneken werd vanaf 27 april 1609 ondergebracht in de school van Oost-Eeklo aan de huidige Oude Houtlei; zij zou daar 's middags blijven eten, behalve op de zaterdagen en op de dagen waarop er bij verplichting naar de mis werd gegaan.

Deze informatie liet toe de auteur te identificeren als de edelman Pieter de Seclyn, zoon van Geeraard uit diens tweede huwelijk met Antoinette de Lalaing. Hij werd schepen van Gent in 1596 (8ste schepen van Gedele), 1603 (5de schepen van Gedele), 1604 (5de schepen van Gedele) en 1611 (5de schepen van de Keure), het jaar van zijn overlijden. (11) Zijn familie leverde overigens meer schepenen in het Gentse stadsbestuur. Hij was gehuwd met Anna van Boneem (+ na 1639), dochter van Philips en Wilhelmina van Hembyse; ook zij behoorde tot de adel. Er bestaat verwarring over hun aantal kinderen. De klassieke genealogische repertoria vermelden vier kinderen: de jong overleden Michiel, Joos, die pater capucijn werd, Jan, heer van Hoogstraten, die in 1636 trouwde met Isabella de Schietere, en Joanna, die in 1626 huwde met Adriaan Borluut, heer van Enode. (12) In de doopregisters van Sint-Baafs, die zeker niet als volledig mogen worden bestempeld, staan ver- 
meld: Michael (7 februari 1598), Joos (11 september 1599), Joanna (4 april 1602) en Philippus (30 augustus 1603). (13) Na het overlijden van Pieter de Seclyn werd er een boedelinventaris opgemaakt ten behoeve van de minderjarige kinderen. In die staat van goed werden er dan weer vier kinderen vermeld, namelijk Joos, Franchois, Jan en Janneken.(14) Dit zijn trouwens de kinderen die in de persoonlijke notities van de auteur voorkwamen. Uit het notieboekje blijkt ook dat Anna van Boneem en haar beide kinderen Joanna/ Jenne en Jan alleszins nog in leven waren op 12 augustus 1639. Zij ondertekenden toen een document aangaande de erfenis van Florence de Seclyn, de zus van wijlen Pierre de Seclyn. Dit document bevindt zich in het hier behandelde manuscript op een niet-gefolieerde pagina.

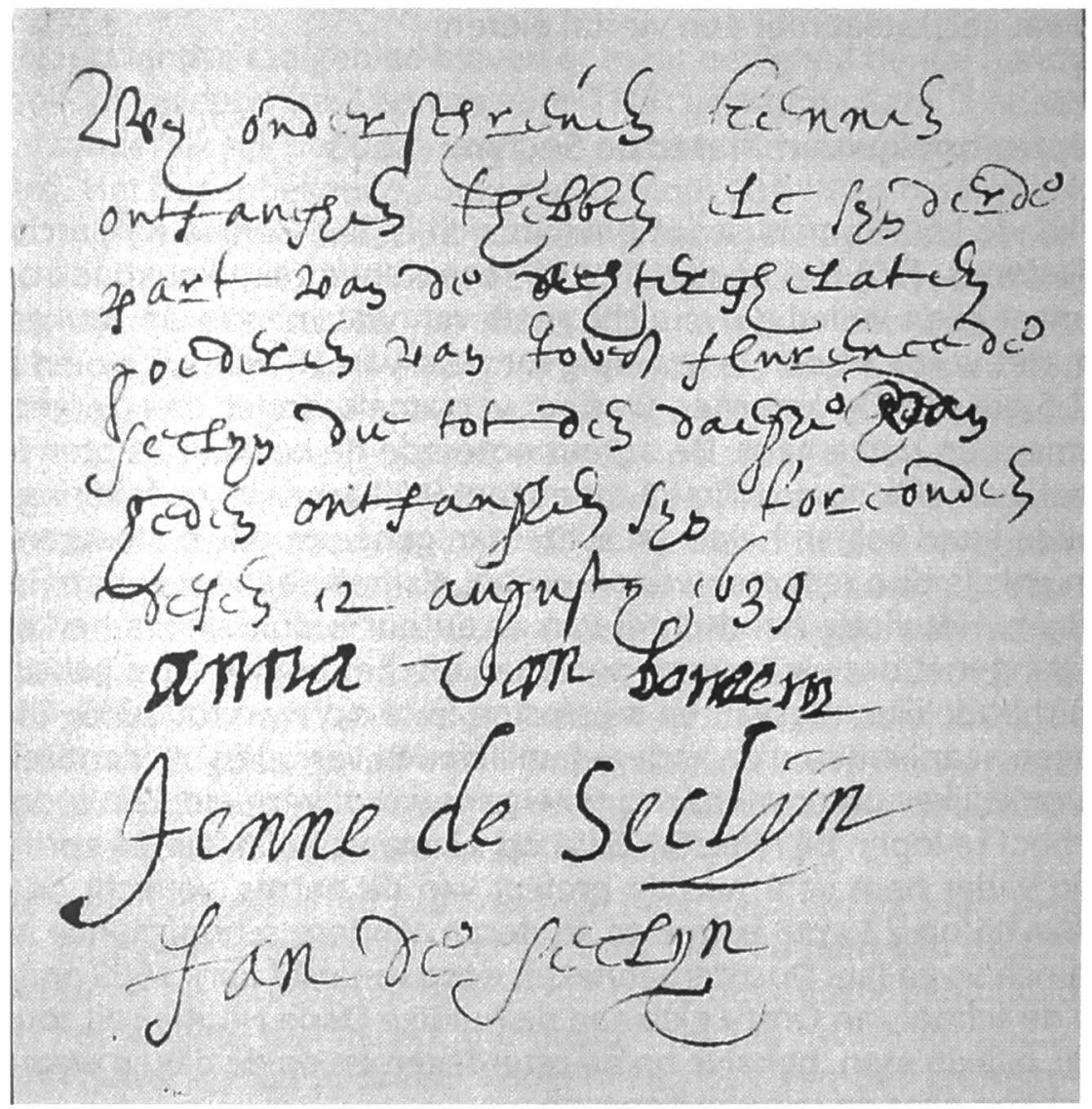

Handtekeningen van Anna van Boneem, de weduwe van Pieter de Seclyn en hun kinderen Jenne en Jan 1639

Jammer genoeg kon de minuut van de voormelde boedelinventaris niet worden teruggevonden. (15) De enige relevante aanwijzing die in de boedelinventaris voorkomt is dat Pieter de Seclyn overleed in zijn woonhuis op de Kouter en dat zijn weduwe en kinderen daar ook bleven wonen.

Talrijke details wijzen duidelijk aan dat Pieter de Seclyn de recepten neerschreef en bijvoorbeeld niet zijn echtgenote, want in de andere notities in zijn handschrift heeft hij het vaak over "myn wyf", zonder haar te noemen. Het valt natuurlijk niet uit te sluiten dat zij hem (een deel van) de recepten dicteerde. Sommige ervan zijn in het Nederlands gesteld en verraden een Gents dialect; andere schreef hij op in het Frans of althans in een Gentse 
versie daarvan. De oudste datum in het manuscript is 1603 . Pieter de Seclyn noteerde dat op 12 oktober van dat jaar hun dienstmeid Susanna in dienst kwam. De kinderlast van Anna van Boneem was aanzienlijk toegenomen en vergde ongetwijfeld de volle aandacht van de vrouw des huizes op. Het mag daarom niet worden uitgesloten dat Pieter de Seclyn de keukenrecepten noteerde die door hem en zijn vrouw op prijs werden gesteld en die dus voor het gebruik van Susanne waren bedoeld. Alles wijst er dus op dat de recepten in 1603 werden opgeschreven.

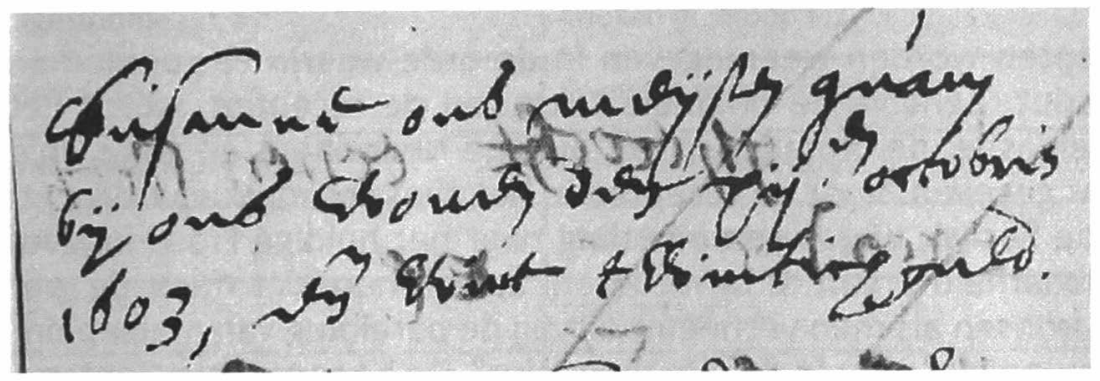

Susanne ons meijsen quam bij ons wonen den 12en octobris 1603, ende wint twintich gulden.

De recepten zelf laten toe enkele algemene indrukken te formuleren. Opvallend is het veelvuldig gebruik van specerijen waardoor de gerechten enkel toegankelijk waren voor meer welstellende families, wat dus inderdaad het geval was bij het echtpaar De Seclyn - Van Boneem. Dit was zeker geen volkskeuken. In de zoute gerechten werd er vaak suiker gebruikt, een kenmerk van de laatmiddeleeuwse keuken. Verder werd er ook overvloedig gebruik gemaakt van eieren en boter, terwijl anderzijds de groenten ontbraken, tenzij in mengsels om vlees of vis te farceren. Fruit kwam in de recepten enkel aan de orde om het voor de winter te bewaren in een suikerstroop gekonfijte vorm, wat waarschijnlijk vaak overeenstemt met wat wij confituur noemen. Bij de sausen speelde de kleur een voorname rol; ze werden bereid met wijn, azijn en verjuis, het bekende gegiste sap met onder meer zure groene druiven en dito appelen. Het vlees of de vis serveerde men vaak op geroosterd brood, overgoten met een lichte soep.

De schotels kenden nog niet de culinaire verfijning die pas in de 18de eeuw en vooral in de 19de eeuw optrad. Zelfs in vergelijking van het in 1612 in Leuven gedrukte "Koocboec oft familieren keukenboec" van Antonius Magirus lijkt de inspiratie van de Seclyn zeer beperkt. (16) De recepten bij Magirus zijn veel meer gedetailleerd en verraden een meer gevorderde culinaire ingesteldheid, met inbegrip van vooral de Spaanse keuken en van andere buitenlandse invloeden. Hij is weliswaar niet ingenomen met het bereiden van vis, maar zijn aandacht voor de bereiding van zeer diverse groenten doet modern aan. Toch moet er hier worden genuanceerd. Vooreerst wist Pieter de Seclyn ongetwijfeld welke recepten Susanne zelf voldoende beheerste en daar zullen de groenten wel toe hebben behoord. Men bedenke verder dat de bereidingen die vandaag de dag in de persoonlijke sfeer worden klaargemaakt, sterk afwijken van wat men in een echt kookboek aantreft. Dat was ten huize de Seclyn niet anders. 
Voor de bereiding maakte het gezin gebruik van de open haard en van de broodoven, waarvan men de warmte inschatte op basis van het moment dat het brood er werd uitgehaald. Een (stenen) fornuis werd niet gebruikt, want dit deed pas algemeen zijn intrede in de de loop van de 18de eeuw. Nergens is er spraak van gietijzeren kookpotten of -pannen, maar wel van potten en platelen in aardewerk.

\section{Recepten}

De recepten worden weergegeven in de orde waarin ze voorkomen in het manuscript. Behalve de originele tekst van de recepten, wordt het boodschappenlijstje, de omtaling in het huidige Nederlands en soms enige commentaar gegeven. Voor de recepten in het alleszins merkwaardige Frans van Pieter de Seclyn, wordt een omtaling naar het huidige Frans ingevoegd om de leesbaarheid ervan te bevorderen. Zo zal men niet meer de wenkbrauwen te fronsen als men verneemt dat bij de bereiding van marsepein "il fault prendre une fille pour le defaire du papier". De hooggeachte Gentse schepen bedoelde gewoon dat men een draad ("un fil") diende te gebruiken om de lekkernij van het papier los te maken. Voor lezers die het Gents beheersen, is de beste raad: Lees de recepten (luidop) in het Gents. Sommige vergelijkbare recepten vindt men in het overzicht van recepten uit enerzijds de edities van de drie eerder vermelde culinaire Gentse receptenverzamelingen in het Middelnederlands van Christianne Muusers (www.coquinaria.nl), en anderzijds uit de Nederlandstalige gedrukte kookboeken van 1500 tot 1800 van Marleen Willebrands (www.kookhistorie.nl). Hierna volgt een receptenlijst die kan helpen bij het terugvinden van een bereiding.

\section{Welke recepten stelde Pieter de Seclyn op prijs?}

\begin{tabular}{|c|c|}
\hline aalbessen (gekonfijte -) f. 8 & aalbessenmoes f. 8 \\
\hline amandelgelei f. $3 v$ & biscuit f. 1 / f. 9 \\
\hline blancmange f. $1 v-2$ & bourbontaarten f. 3 \\
\hline braadvarken (saus voor -) f. 5 & damaspruimen (gekonfijte -) f. 8 \\
\hline damastwater f. $8 v$ & deegsels f. 7v \\
\hline duivenpastei (warme -) f. $4 \mathrm{v}$ & eend (saus voor -) f. 5 \\
\hline farce voor haantjes, kippen en ganzen $f .3 v$ & gans (saus voor -) f. 5 \\
\hline gevogelte (saus voor -) f. 4 & gekonfijte aalbessen f. 8 \\
\hline gekonfijte damaspruimen f. 8 & gekonfijte gember f. $2 v$ \\
\hline gekonfijte kersen f. $7 v-8$ & gekonfijte kweeappels f. $2 v$ \\
\hline gekonfijte oranjeschillen f. $2 v$ & gele saus f. $5 v$ \\
\hline gember (gekonfijte -) f. $2 v$ & godenaak f. 8v-9 \\
\hline grondelingensoep f. 4 & haantjes, kippen en ganzen (farce voor -) f. $3 v$ \\
\hline
\end{tabular}




\begin{tabular}{|c|c|}
\hline hypocras f. 3-3v / hypocras (eenvoudige -) f. 2v & kalfsbroodjes (gestoofde -) f. 6 \\
\hline kalfslever (gebraden -) f. 1v & kapoen (gesmoorde -) f. 5 \\
\hline karper (gestoofde -) f. $5 v /$ f. $6 v$ & karperpastei f. $8 v$ \\
\hline karpersoep f. $6 \mathrm{v}$ & kersen (gekonfijte -) f. 7v-8 \\
\hline kerveltaart f. 6 & kippencoulis f. $4 \mathrm{v}$ \\
\hline koevoet (gestoofde -) f. 5 & krieken in stroop f. 2 \\
\hline kriekentaart f. 5v-6 & kwee (gelei van -) f. $2-2 v$ \\
\hline kweeappels (gekonfijte -) f. $2 v$ & lams - of schapenbout f. 5 / gesmoorde - f. $5 \mathrm{v}$ \\
\hline lombardisch ei f. $4 \mathrm{v}$ & lombardische taart f. 6 \\
\hline marsepein f. 7-7v & melkbrood f. 1 \\
\hline oranjeschillen (gekonfijte -) f. $2 v$ & oublies f. $6 v$ \\
\hline palinggalantine voor tijdens de vasten f. $6 \mathrm{v}-7$ & pastei (karper-) f. $8 \mathrm{v}$ \\
\hline pladijs (gestoofde -) f. $4 v$ & rijstdessert f. 3 \\
\hline rozen parfumeren f. $3 \mathrm{v}$ & saus (gele -) f. $5 v$ \\
\hline saus voor braadvarken f. 5 & saus voor eend f. 5 \\
\hline saus voor gansf. 5 & saus voor gevogelte f. 4 \\
\hline saus voor snip f. $5 v$ & saus voor wildbraad f. $4 v-5$ \\
\hline schapen- of lamsbout f. 5 / gesmoorde - f. $5 v$ & schapenbout f. 1v/f. 5 \\
\hline sneeuw f. 7 & snip (saus voor -) f. $5 v$ \\
\hline snoek (gefarceerde -) f. 1-1v & snoek (gestoofde -) f. $6 v$ \\
\hline snoek (-soep) f. $4 v$ & snoek of karper in pastei f. $8 \mathrm{v}$ \\
\hline soep (grondelingen-) f. 4 & soep (karper-) f. 6v \\
\hline soep (snoek-) f. $4 v$ & Spaanse pap f. $2 v-3$ \\
\hline speenvarken of biggetje f. 4 & spreten $\mathrm{f} .7 v$ \\
\hline stekelbessenmoes f. $4 v$ & stukkenbrood f. 6 \\
\hline suikerdeeg f. 9 & taart (kervel-) f. 6 \\
\hline taart (krieken-) f. 5v-6 & taart (Lombardische -) f. 6 \\
\hline taart (wrongel-) f. 6 & tourten $\mathrm{f} .1 \mathrm{v}$ \\
\hline uier (gesmoorde -) f. 6 & uierpastei f. 6v \\
\hline varkensribbetjes f. $5 v$ & vinken (gestoofde -) f. 3v-4 \\
\hline wildbraad (saus voor -) f. 4v-5 & wrongeltaart f. 6 \\
\hline
\end{tabular}


f. 1 - Melkbrood - "Pour faire du pain de laict - II fault prendre du fyn fleur qui soit reboute par plussieurs fois et de bien bon ghij et en lieu deauwe de prendre de bon laict, et de le faire bien petrijer iusques alors quil soit ung petit dure et estant ainsij petrije de ij mectre encore du laict en faisant iusques a trois ou quatre fois, outant de laict que le paste pourat en boire comment faict avecques de leau et apres de faire de petit pain en mectant lun sur laultre et de mectre ou four comment on faict daultre pain".

Omtaling: Pour faire du pain de lait - Prenez de la fine farine qui a été tamisée à plusieurs reprises, assez bien de bonne levure et du bon lait au lieu de l'eau [du pain ordinaire]. II faut bien pétrir la pâte jusqu'à ce qu'elle devienne assez rigide. Ajoutez alors du lait et répétez ce procédé aussi longtemps que la pâte absorbe le lait, de la même manière que vous le faites avec de l'eau. Formez de petits pains en les tassant l'un sur l'autre et mettez les au four comme vous le faites pour du pain ordinaire.

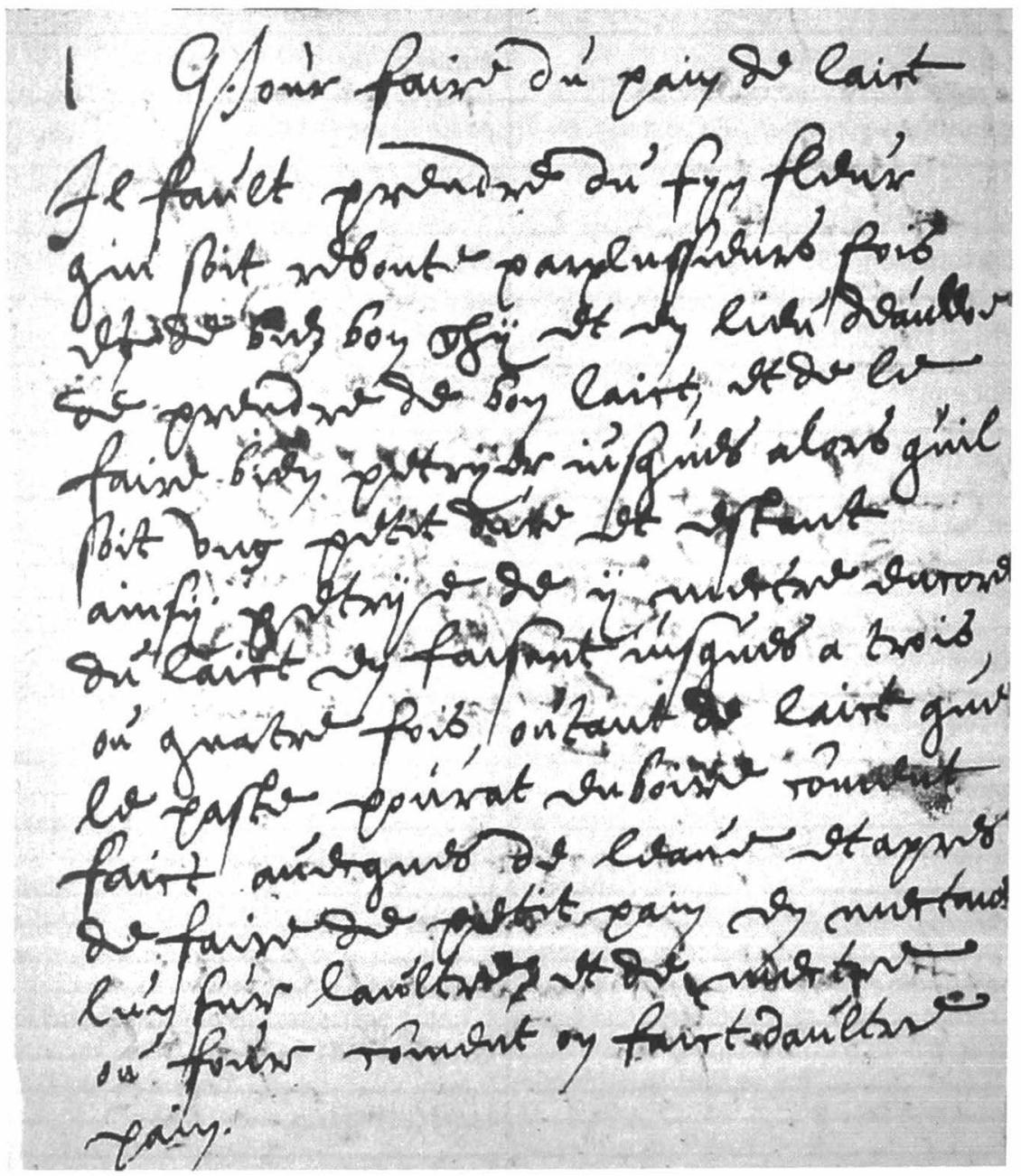

Recept voor melkbrood

Ingrediënten: fijne bloem - gist - melk.

Bereiding: Meng de gezeefde fijne bloem met de gist en de volle melk en kneed tot het deeg stevig wordt. Voeg er dan weer melk bij en herhaal dat 
drie of vier maal, zo lang als het deeg de melk opneemt, zoals je dat doet met water in gewoon brood. Vorm dan kleine broodjes en bak ze in de oven zoals gewoon brood.

f. 1 - Biscuit - "Pour faire du bisquit - II fault prendre du fin sucre et de fleur aultant d'ung que de laultre ou selon vostre discretion, anijs de coliandre, estampez du muscq remellez avecques de leaue de roses à vostre discretion, après prendrez des oeufs tresbien batus en mellant avecques lesdites choses, iusques qui soient bien mellez en forme dugne patte mediocrement molle comme paste de raton et après le metterez sur du papier par drences, et le metterez den ung four moiennement saut et le lesserez audit four iusques qui soit ung peu secq et aprez le tiererez hors du four et lesserez ainsij refroidijr et quant il sera refroidij alors le fault trenser par pieces et le remectre au four moiennement saut".

Omtaling : Pour faire du biscuit - $\|$ faut prendre à discrétion une quantité égale de sucre fin et de farine, de l'anis, de la coriandre. Pilez du musc avec de l'eau de roses à discrétion. Ajoutez des jaunes d'œuf bien battus et mélangez tous les ingrédients en formant une pâte plutôt molle comme de la pâte de " raton ". Étalez cette pâte coupée en tranches sur du papier et mettez-les dans un four moyennement chaud pour les faite sécher. Retirez-les du four et laissez les refroidir. Coupez-les en pièces et remettez-les au four moyennement chaud.

Ingrediënten: even veel fijne suiker als bloem, naar eigen voorkeur - anijs koriander - muskus - rozenwater - eieren

Bereiding: Voeg de ingrediënten samen, waarbij de muskus werd fijngestampt met rozenwater. Vermeng dit met zeer stevig geklopte eierdooiers en maak er een middelmatig zacht deeg van, zoals "paste de raton", mogelijk pannenkoekendeeg. Snij het in schijven, leg deze op papier en laat ze in een middelmatig warme oven enigszins uitdrogen. Verwijder ze uit de oven en laat ze afkoelen. Snij ze in stukken en breng die opnieuw in een middelmatig warme oven.

Commentaar: Christianne Muusers verwijst in haar glossarium bij het handschrift in KANTL hs. 15 ter verklaring van "rasschoen" naar een soort pannenkoek, naar het Franse "raston", een term die verschillende gerechten kan aanduiden.

f. 1-1v - Gefarceerde snoek - "Pour accoutrer brochet au lart - II fault boillijr au bleu en vinaigre de vin sensuijt la sauce prennez du bure et du lart trenches en forme de deez et ij mectre ensamble au feu iusques que le lart soit quasi fondu et apres prendre le lard ce que nest pas fondu et ij adiouster avec le lard et bure fondu ung peu de oignons selon vostre appetit bien menu ache et ung petit de vin et du poivre et nois de muscate et lesser cesdictes choses bouileir ung petit ensamble apres le mettre sur le broche".

Omtaling : Brochet farci au lard - Bouillez le brochet au bleu dans du vinaigre de vin. Prenez pour la sauce du beurre et du lard en tranches coupées en dés. Mettez le lard sur le feu jusqu'à ce qu'il soit pratiquement tout fondu. Ajoutez-y le beurre fondu, des oignons hachés menu à discrétion, un peu de 
vin, du poivre et de la noix de muscade et laissez mijoter. Nappez le brochet de cette sauce.

Ingrediënten: een snoek - wijnazijn - boter - spek - wijn - peper - muskaatnoot.

Bereiding: Kook de snoek blauw in wijnazijn. Neem voor de saus boter en spek in dobbelstenen. Als het spek nagenoeg gesmolten is, voeg je er fijn gehakte ui, een scheut wijn, peper en muskaatnoot aan toe. Laat dit samen garen en giet het over de snoek.

f. 1v - Schapenbout - "Pour acher ung jugo du mouton - II fault premierement lever la peau de seure un petit espes et apres de trencher le milleu dudict dehors et bien batre avecq le dois dung cousteau et aprez prendrez du persin folije de noix muscate et mieulx doeufs hares bien menu ensamble avec ung petit de lard et apres remectre lesdites trences dedans vostre mouton et a la fin recoudre ledicte peau tellement quil soit bien serré et le mectre a la broche".

Omtaling : Pour hacher un gigot de mouton - Il faut tout d'abord souslever la peau sur une certaine largeur et couper de sorte qu'il vous soit possible d'enlever la chair de l'intérieur. Battez-la fortement avec le dos d'un couteau. Mélangez la viande avec du persil, du macis, de la noix de muscade et des jaunes d'œuf. Hachez tous ces ingrédients avec un peu de lard. Remettez les tranches dans le mouton et recousez-le afin de le refermer fermement. Puis vous mettrez le gigot à la broche.

Ingrediënten: een schapenbout - peterselie - foelie - muskaatnoot - eieren een weinig spek.

Bereiding: Maak eerst maakt de huid los. Haal het onderliggende vlees eruit en sla er stevig op met de rug van een mes. Maak een farce met peterselie, foelie, muskaatnoot, eieren en een weinig spek. Stop daarna het in schijven gesneden vlees en de farce terug, naai de huid stevig dicht en steek de bout aan het spit.

f. Iv - Gebraden kalfslever - "Om calver lever te braden - Neempt die lever ende wint die int netken ende steekse vol goede cruiden ende so braden ende over ghietse met de sauce van eenen hase".

Ingrediënten: kalfslever - een netje - goede kruiden - hazensaus.

Bereiding: Stop de kalfslever met goede kruiden in het netje en laat dit braden. Overgiet met hazensaus.

f. $1 v$ - Tourten - "Om tourten te maecken - Neempt spaensche pap ende maect u deech drij vinghers hooghe ende leght de pap daer in boven de pap suldij legghen maerck alsoo gheel als ghij mocht ende corynthen ende stroijen daer up naghel pour dan suldij den scheel ofte decksel vier ofte vijf dijcke maecken ende dat alsoo dunne als ghij cant ende dat opperste deech moet boven al ghesneden zijn, dan gaen die kusten al van een als sij ghebacken syn".

Ingrediënten: Spaanse pap (zie het recept f. 2v-3) - deeg - merg - krenten - 
Bereiding: Voorzie uw deeg van een drie vinger hoge rand en giet er de Spaanse pap in. Leg daarboven zoveel mogelijk merg om de pap te overdekken en bestrooi met krenten en kruidnagelpoeder. Rol 4 of 5 deegdeksels zo dun mogelijk uit en breng kerven aan in het bovenste deksel zodat de korst uiteenvalt na het bakken.

f. 1v-2 - Blancmangé - "Om te maecken blan mangier - Om een pinte zoetemelck zoo moet ghij nemen twee onsen blomme daer toe twee onsen sueker, ghij sult de blomme met de melck tsaemen tremperen doen daer toe roosewaeter ende laet dit tsaemen sieden sonder op hauwen van roeren tot dat gheheel dicke beghint te sijne, dan sult ghij nemen het witte van eenen cappoen ende pleucht dat alsoo cleene als ghij condt, ende stroijen dat in die pap als hij beghint te dicken met het suicker, ende laeten dat zoo langhe zieden dat die pap soo dicke es dat men snijde met een mes, ende als ghesoden es ghietet in een patteel ende snidet in sneden".

Ingrediënten: $57 \mathrm{cl}$ zoete melk - $54 \mathrm{~g}$ bloem - $54 \mathrm{~g}$ suiker - rozenwater - wit vlees van een kapoen.

Bereiding: Voeg de bloem bij de melk, giet er rozenwater bij en laat dit onder voortdurend roeren koken tot het gaat indikken. Pluis het wit van een kapoen zo klein mogelijk en strooi het samen met de suiker op de pap als die begint te koken. Laat hem zo lang indikken tot je hem met een mes kan snijden. Giet dan in een platte schotel en snij er schijven van.

f. 2 - Krieken in stroop - "Om criecken in de cijrope - Neempt vier pont criecken tot een pont suickers ende een pinte waters met wat sop van criecken ende maect u cijrope met u suicker ende het water, ende als u cijrope wat versleghen es doet dan daer u criecken in, ende laetse sien naer u goetdijncken".

Ingrediënten: 1,734 kg krieken - 433 g suiker - $57 \mathrm{cl}$ water - een weinig kriekensap.

Bereiding: Breng de suiker met het water en het kriekensap aan de kook tot het een dikke stroop wordt. Laat die een tijdlang rusten. Voeg er de kersen aan toe en laat verder koken naar believen.

f. 2-2v-Gelei van kwee - "Recepte om te maecken geleije van queen-Neempt eenen schoonen nieuwen pot daer in gheleijt eerst een hauten deurgaette telloire ende legghet daer up de queen peeren ofte appels in vier quartieren ghesneden ende die clochuysen uut ghedaen ende vult de pot up hoopte ende overdect hen met een deeghen decsel wel toe ende dan stellen in eenen hoven wel heet ghelijck om groot broot te backen twee heuren lanck ofte bet, ende dan neempt den pot uut ende weert de peeren ende neempt tsop onder de telloire ende neempt suicker alsoo veele van ghewichte als dat sop weecht ende siedet te gaedere tot dat gheleyt ende dan ghietet in schoone teelkens".

Ingrediënten: kweeperen of -appels - suiker.

Bereiding: Snij de kweeperen of -appels in vieren en verwijder het klokhuis. Leg ze in een nieuwe aarden pot op een houten schaal met gaten. Vul de pot 
tot bovenaan en sluit hem goed af met een deegdeksel. Plaats hem gedurende twee uren of meer in een behoorlijk hete oven zoals voor het bakken van groot brood. Neem de pot eruit en verwijder de vruchten. Neem enkel het sap onder de houten schaal en voeg er evenveel suiker aan toe als het gewicht van het sap. Laat dit samen koken tot de gelei zich vormt en giet deze over in propere teiltjes.

f. $2 v$-Kweeappels - "Om te maecken gheheele queappels - Men neempt IX appels ende laeten sieden in waetere tot dat sij meurwe sijn ende dan neempt een pinte van dat waeter ende een pont suicker ende daer cijrope af ende laetse soo confijten".

Ingrediënten: 9 kweeappels - water -430 g suiker.

Bereiding: Kook de kweeappels zacht in water. Kook stroop met $57 \mathrm{cl}$ kookwater en de suiker en laat de kweeappels daarin konfijten.

f. $2 v$ - Gekonfijte oranjeschillen - "Om te confijten schellen van oraingen Ghij moet nemen vier pont suicker tot den XXV appelen ende nemen onder pinte wijns om u cyrope te maecken ende die schellen te weecken legghen eenen nacht int waeter de schellen moeten eerste nieuwe ghesoden sijn".

Ingrediënten: 1,734 kg suiker - 25 sinaasappels - $57 \mathrm{cl}$ wijn - water.

Bereiding: Laat de verse schillen een nacht in water weken. Maak stroop met suiker en wijn.

f. $2 v$ - Gekonfijte gember - "Om ghijnebeer te confijten - Men zal nemen een pont ghynebeers daer toe nemen een pinte waters ende een alf pont suickers settende dezelve pinte waters met den suicker voorseijt te sieden alleene tot op de heelft, aldus ghesoden wesende sal men de voorseijde ghijnebeere doen in de voorseijde substancie laten tsamen sien dat dicke ghenoech es".

Ingrediënten: $433,5 \mathrm{~g}$ gember $-57 \mathrm{~d}$ water $-217 \mathrm{~g}$ suiker.

Bereiding: Laat het water met de suiker tot de helft inkoken. Voeg er de gember aan toe en laat dit verder koken tot het voldoende ingedikt is.

f. $2 v$ - Eenvoudige hypocras - "Om te maecken slechten hypocras - Om te maecken eenen stoop ghij moeten nemen vijf pinten wijn daer toe moet ghij hebben een pint suicker ende een once een alf cecien min caneele ende een alf seceijn ghynebeere ende stampen al tsamen ende legghet te weec een heure of twee ende steecket dan deur eenen hijpocras sack tot dat claer es".

Ingrediënten: 2,88 I wijn - 570 g suiker - 23,6 g kaneel - 3,37 g gember.

Bereiding van 2,3 I hypocras. Stoot de specerijen samen en laat de ingrediënten twee uur lang weken. Wrijf het dan door een hypocras-zak tot het helder is.

Opmerking: Een hypocras-zak is een puntvormig toelopende zak gemaakt van een dicht geweven stof, die werd gebruikt als fijne zeef om de hypocras te klaren. 
f. 2v-3 - Spaanse pap - "Om spaenschen pap - Een pinte melck, vier eijers, een lepel witte blomme, dit als tsamen doerstecken ende een lepel roosewaeter ende stellet al te tsamen te siene ende doetter dan suicker in".

Ingrediënten: melk - eieren - witte bloem - rozenwater - suiker.

Bereiding: Wrijf $57 \mathrm{cl}$ melk, 4 eieren en een lepel witte bloem door een zeef en voeg er een lepel rozenwater aan toe. Breng dit aan de kook en voeg er suiker aan toe.

f. 3 - Bourbontaarten - "Om te maecken borbonnoissche taerten-Eerst moet ghij nemen een vierendeel zoete melck ende $X$ eyeren ende suicker ende suffraen naer u goetdijncken ende dat al tsaemen sien ende dan moet ghij legghen in u deech."

Ingrediënten: $28,75 \mathrm{cl}$ melk - 10 eieren - suiker en saffraan naar believen deeg.

Bereiding: laat de ingrediënten samen koken en leg dit uit in deeg.

Opmerking: er wordt van uitgegaan dat een vierendeel melk gelijk is aan een kwart van 1 pot van 1,15 I.

f. 3 - Rijstdessert - "Om rijs te maecken - Eerst neempt een alf vierendeel rijs daer toe eenen pot soetemelc daer inne laettet weecken ende dan laetet wel slecht sien, daer naer nemen drij ofte vier eijeren ende eenen lepel ofte twee fijne blomme dat al tsaemen slaen, maer ten moet niet dicke zijn ende dan nemen een ijseren panne eet ende lettel smaels of claere boter ghesmolten nemen, dan eenen lepel schept van den rijst ende legghet in die panne ghelijck of ghij schenen biect".

Ingrediënten: 54 g rijst - 1,15 I zoete melk - eieren - fijne bloem - smout of boter.

Bereiding: Laat de rijst weken in melk en breng voorzichtig aan de kook. Roer er 3 of 4 eieren en 1 à 2 lepels fijne bloem doorheen, maar laat het mengsel niet te dik worden. Verhit een ijzeren pan met een weinig gesmolten smout of heldere boter en schep de rijst met een lepel in de pan en laat het bakken, zoals met "schenen" (?).

Opmerking: "schenen", schijven, maar wellicht een plat gebak.

f. 3-3v - Hypocras - "Pour faire ung lot dypocras - Prenez ung unce et demije de fine canelle, ung unce de cloux ou de bon refuijs demij unce de noix, demij unce de grienne le tout batu bien plat sans pile en poudre, mettre dedans demij pot de vin et laiser le reposer ungne heure, après prenez ung livre et ung quart de suicre et le melles avecq aultre demij lot du vin et le faictes bouillijr tant que le suicre soit fondu puis le mettez avec vostre hijpocres dedans ung pot ou telle et ayes prest demij pinte de bon laict pour ietter astivement dedans votre hypocras pour le faire clair, puis laissez le reposer ungne heure ensamble après le passerez par le sacq de lijpocras tant quil soit clair".

Omtaling : Pour préparer un lot [een stoop] d'hypocras - Prenez une once 
et demie de fine cannelle, une once de clous [de girofle] ou de bon "refuijs» [macis?], une demi once de noix [de muscade], une demi once de grains du paradis. Battez énergiquement le tout en poudre sans gruaux en mettez le mélange dans un demi pot de vin. Après avoir laissé reposer une heure, ajoutez-y une livre et quart de sucre. Mêlez-le avec un autre demi lot de vin et faites bouillir jusqu'à ce que le sucre soit fondu. Puis vous verserez cette préparation avec votre hypocras dans un pot ou écuelle et ayez prêt une demi pinte de bon lait pour le jeter rapidement dans votre hypocras pour le clarifier. Laissez reposer une heure ensemble et passez par le sac à hypocras jusqu'à ce que celui-ci soit clair.

Ingrediënten: $40 \mathrm{~g}$ fijne kaneel - $27 \mathrm{~g}$ kruidnagel of goede "refuijs" (wellicht foelie) $-13,5$ g muskaatnoot - 13,5 g grienne of paradijskorrels $-1,73$ I wijn $-28 \mathrm{cl}$ melk.

Bereiding van 2,3 I hypocras. Alle specerijen goed stoten zonder er poeder van te maken. Dit toevoegen aan $57 \mathrm{cl}$ wijn en een uur laten rusten. De suiker mengen met nog 1,15 I wijn en aan de kook brengen. Dan de melk in éénmaal bijgieten om de hypocras te klaren. Samenvoegen en een uur laten rusten en dan door de hypocraszak gieten om hem te klaren.

Opmerking: Met "grienne" of "greyn" worden paradijskorrels bedoeld, dit is een soort peper afkomstig uit Afrika van de "Aframomum granum-paradisi" of van de "Aframomum melegueta". Frans "graine du paradis".

f. $3 v$ - Rozen parfumeren - "Om roosen te parfumeren - Neempt violetten pouder ende byngewijn en naghels ende caneele stract van elcx om een stuver ende minghelt daer toe een alf pinte waters van damast ende twee lepels vliender azijn, doet dit al te tsamen met u roosen, ende doeghet al tsamen in eenen nieuwen pot ende stopten al nauwe toe met deech ende stelten in eenen hoven als het broot uutgaet".

Ingrediënten: viooltjespoeder (17) - benzoë - kruidnagel - kaneel - 28,8 cl damastwater (18) - twee lepels vlierazijn - deeg.

Bereiding: Voeg de ingrediënten samen met de rozen in een pot. Sluit die goed af met deeg en plaats hem in de oven als het brood eruit komt.

f. $3 v$ - Amandelgelei - "Om te maecken geleije van amandels - Neempt een pinte zoetemelck ende neempt een alf unce huis blat ende X ofte XII amandels ghestampt ende neempt die heelft van die melck ende stelt het huisblat te weecke in die melck ende doeter inne foeille ende noten ende steecket door eenen sacq".

Ingrediënten: $57 \mathrm{cl}$ zoete melk - 13,5 g huisblas - 10 tot 12 amandelen - foelie - muskaatnoot.

Bereiding: Laat de vislijm weken in de helft van de melk. Voeg er de amandelen, foelie en muskaatnoot aan toe. Zeef het mengsel door een zak.

Opmerking : "huis blat", huisblas, dit is vislijm in blaadjes dat als bindmiddel werd gebruikt. 
f. 3v - Farce voor haantjes, kippen en ganzen - "Om te maecken faessel om ancken, kiekens, gansen te fasen - Neempt die lever ende capse met goede cruiden te weten spenaige, letuwe, persijn, saille, ysopie, mayoleijne, pijlijoen, roosmarijn ende wat laert ende als wel cleen ghecapt es, fruitet in die boter wel nieuwe ende doeter in drij ofte vier eijers ende note muscate ghynebeere pour ende dat mede zult gij fasen".

Ingrediënten: de lever van het gevogelte - goede kruiden, namelijk spinazie, latuw, peterselie, salie, hysop, marjolein, tijm en rozemarijn - wat spek - verse boter -3 of vier eieren - muskaatnootpoeder - gemberpoeder.

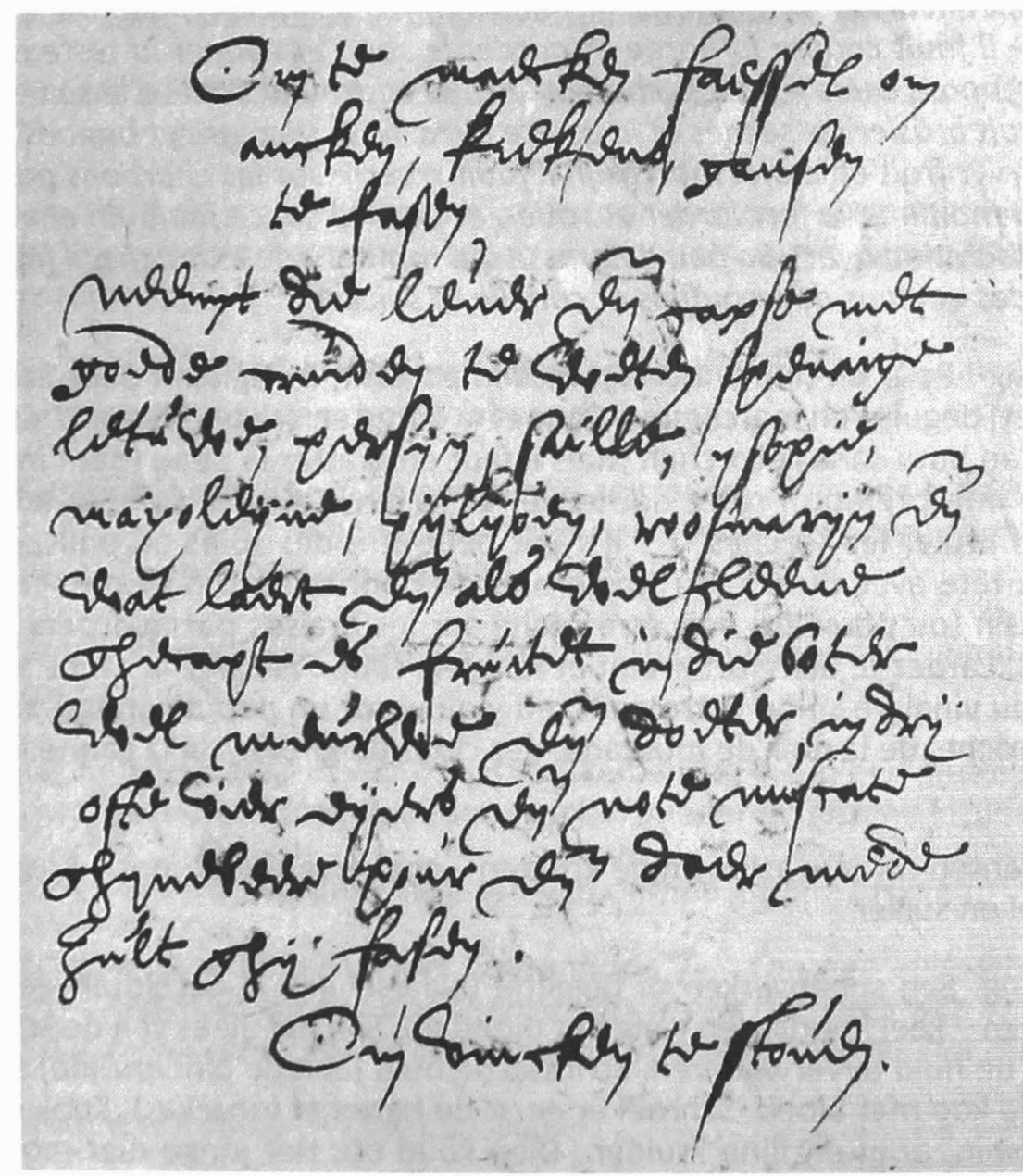

Farce voor haantjes, kippen en ganzen

Bereiding: Hak de lever, de kruiden en het spek fijn. Fruit dit mengsel in verse boter. Meng er de eieren en de specerijen onder en gebruikt dit om te farceren.

f. 3v-4 - Vinken - "Om vincken te stoven - Neempt wyn suicker tornesol canel poeder, en cleen perre stecken smoort die al te samen, dan neempt $u$ vincken die wel nieuwe ghesoden sijn ende fruitse in de brune botere met wittebroot sticxkens terlijnc groot ghesneden wel stijf ghebacken ende leghtse in pateel en ghiet dat ghesmoorde daer hover". 
Ingrediënten: vinken - wijn - suiker - tournesol - kaneelpoeder - "cleen perre stecken" [onduidelijk, mogelijk prei] - bruine boter - wittebrood.

Bereiding: Bereid de saus met wijn, suiker, tournesol, kaneelpoeder en "cleen perre stecken". Fruit de vers gekookte vinken in bruine boter met in dobbelstenen gesneden gebakken wittebrood. Leg ze in een platte schotel en giet de saus erover.

Opmerking: "tornesol", tournesol - een rode tot violette of blauwe kleurstof, gewonnen uit verschillende planten of korstmossen. (19)

f. 4 - Speenvarken of biggetje - "Pour ung (niet ingevuld) deghise en marcasijn - II fault couper la gorge et garder le sang et couper la teste en hure sans eschorce, mais il fault eschorcer le cuirs et drougier aveca le san et la teste il fault brusler les secnes et le quiere avec vin et vinaigre et bonnes herbes et le servyr froit et le dict marcasijn il fault reserre sur les charbons par quartiers ou moitie et le fort larder et rotier, et pour la sauce fault vin et vinaigre selon discretion avecs un peu de gresse qui tombera de la broche, il fault nois muscades et clous de ierouffels et canelle et suicker".

Omtaling : Pour un (il manque un mot important, il s'agissait peut-être d'un porcelet) déguisé en marcassin - Coupez la gorge en gardez le sang. Découpez la tête en hure sans l'écorcher. Mais il faut en gratter la peau (par l'intérieur - cette interprétation reste douteuse) et la farcir avec le sang. II faut tout d'abord brûler les "secnes" ( ? il s'agit peut-être des soies ou poils). Cuisez alors la tête avec du vin, du vinaigre et de bonnes herbes. Servez froid. Le marcassin (ou porcelet) doit être séché sur les braises par quartiers ou par moitiés. Lardez-le bien fortement et faites-le rôtir. Préparez la sauce avec du vin et du vinaigre selon votre goût, en y ajoutant un peu de graisse tombée de la broche, de la noix de muscade, des clous de girofle, de la cannelle et du sucre.

Ingrediënten : wijn - azijn - fijne kruiden - spek - muskaatnoot - kruidnagel - kaneel en suiker.

Bereiding: Een speenvarken of biggetje (waarschijnlijk) bereid als een jong everzwijn - keel het dier en vang het bloed op. Snij het vlees van de kop klein zonder de huid te verwijderen. Schraap de huid (aan de binnenzijde) schoon en vil de kop met bloed. Schroei er eerst de haren af (onzeker). Kook dan de kop in wijn, azijn en fijne kruiden. Dien koud op. Het jonge dier moet vervolgens in kwartieren of helften worden gedroogd op de hete (houts)kolen. Bekleed dit overvloedig met spek en braad het aan het spit. Bereid de saus met wijn en azijn naar wens, voeg er enig vet aan toe dat van het braadspit is gedropen, en verder muskaatnoot, kruidnagel, kaneel en suiker.

Opmerking: de interpretatie van de Franse tekst blijft problematisch.

f. 4 - Grondelingensoep - "Om grondellynck soppen - Neempt vin en verguis ghinebeer suicker ende boter ende groen cruiden wel cleene ghesneden laet al te saemen sien met de grondelinghen, dan neempt rosteijen van witte broot leghse in de pateele ende ghiet al het voorseyde daer up".

Ingrediënten: grondelingen - wijn - verjuis - gember - suiker - boter - groe- 
ne kruiden - geroosterd wit brood.

Bereiding: Kook de grondelingen met wijn, verjuis, gember, suiker, boter en groene kruiden. Leg schijven geroosterd wit brood in een schotel en giet er het kooksel overheen.

Opmerking: de "Gobio gobio", grondeling of riviergrondel, in het Frans "goujon", is een kleine karperachtige die in onze rivieren werd gevangen.

f. 4 - Saus voor gevogelte - "Om sauce tot gebraen voghels - Lijfcoucke gheweeckt ende deurghesteken met veers sop daer in ghedaen bruin boter, naghelpoer ende peper, laurier blaeren ende wat roosmarijn".

Ingrediënten: peperkoek - vers "sop" - gebruinde boter - kruidnagelpoeder - peper - laurierblaren - rozemarijn.

Bereiding: Wrijf de geweekte peperkoek door een zeef en meng met verse bouillon. Voeg daarin gebruinde boter, kruidnagelpoeder, peper, laurierblaren en rozemarijn

Opmerking: "veers sop" of "vessop" komt een aantal malen voor en verwijst wellicht naar een of andere bouillonbereiding.

f. $4 v$-Gestoofde pladijs - "Om een pladijs te stoven - Snijt een pladijs in vier ofte zes sticken, leghse in een pateel, dan neempt veriuis boter naghel poer ghinebeer poer ende wat groen cruit".

Ingrediënten: een pladijs - verjuis - boter - kruidnagelpoeder - gemberpoeder - groene kruiden.

Bereiding: Snij de pladijs in vier of zes stukken en leg die in een platte schotel met verjuis, boter, kruidnagelpoeder, gemberpoeder en groene kruiden.

Opmerking: "veriuis", verjuis - zuur sap van onrijpe groene druiven.

f. $4 v$ - Lombardisch ei (een soort "zabaglione") - "Om een eij lombaert te maecken - Men moet tot een door hebben drij lepels rijnschen wijn ende suycker tot dat wel zoete zi, roeret in een pateel up heete colen tot dat dicke es".

Ingrediënten: eierdooier - rijnwijn - suiker.

Bereiding: Per dooier neemt men drie lepels rijnwijn en suiker om het goed te zoeten. Roer het in een schaal op gloeiende kolen tot het stijf is.

f. $4 v$ - Stekelbessenmoes - "Om stekelmoes te maecken - Siet stekelbesien in wijn ende suicker tot datse meurwe sijn doetse door een stamijne ende doet er een eij in ende caneel poeder ende sietse weder".

Ingrediënten: stekelbessen - wijn - suiker - een ei - kaneelpoeder.

Bereiding: Kook stekelbessen in wijn en suiker tot ze zacht zijn. Wrijf ze door een zeef. Voeg er een ei en kaneelpoeder aan toe en laat verder koken.

f. 4v - Klppencoulls - "Om colis te maecken - Siet een groot kieken wel meur- 
we met specerie of goede cruiden, neempt daer af den spirijnck ende bitter amandels stampet zeer cleen, doeghet door een stamijne met den zelven zope daer den capoen in ghesoden es doet daer in suicker naer u goetdijncken ende ghevet den siecken al waerme te dryncken".

Ingrediënten: spiering van een grote kip - specerijen of goede kruiden - bittere amandelen - suiker.

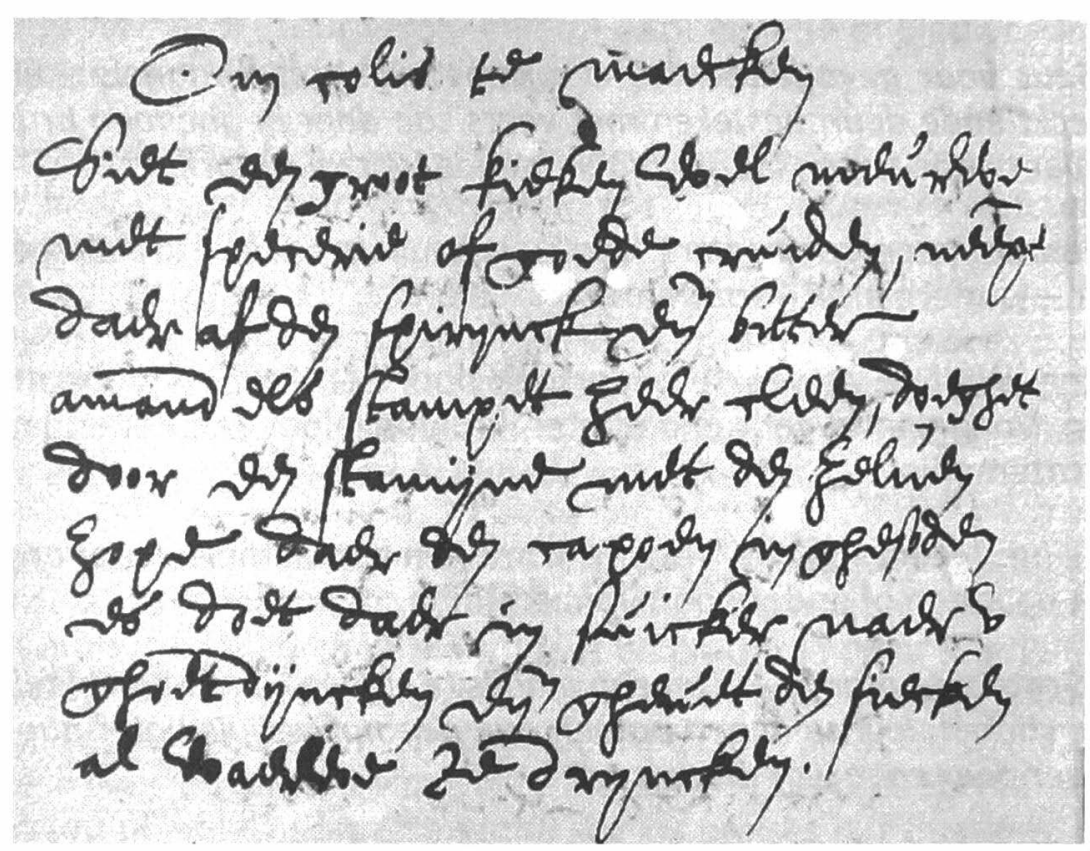

Kippencoulis

Bereiding: Kook de kip zeer zacht met specerijen of goede kruiden. Neem de filet en stamp die fijn met de bittere amandelen. Roer dit door een zeef met het kookvocht van de kip doe er suiker in naar believen. Geef dit warm te drinken aan de zieke.

Opmerking: spiering is normaal het stuk vlees tussen de nek en de schouder van het varken, hier wellicht kipfilet. Een "stamijne" is een zeefdoek, vgl. Frans "étamine".

f. $4 v$ - Snoeksoep - "Om snouc soppen - Pelt u snoucken sonder screpen met den steert in de mont neempt wijn veriuis ende een lettel soffraen ende boter ende witte wittebroot gheroost ende leght tvis daer op metten zope".

Ingrediënten: snoeken - geroosterd wit brood - wijn - verjuis - saffraan - boter.

Bereiding: Ontvel de snoeken zonder ze eerst te ontschubben en stop de staart in de muil. Kook de vis met wijn, verjuis, een snuifje saffraan en boter en serveer hem op geroosterd wit brood overgoten met het kookvocht.

f. $4 v$ - Warme duivenpastei - "Om een duve pasteije waerme te dienen Leghtse in wit deech maer sij moet eerst ghefrobolleert sijn en doeter in roosmarijn, tymes ende not poer ende ghynebeer poer ende persijn ende druven 
ofte stekelbesien ende boter naers goetdyncken".

Ingrediënten: Gekookte en ontbeende duif - rozemarijn - tijm - muskaatnootpoeder - gemberpoeder - peterselie - druiven of stekelbessen - boter naar believen

Bereiding: Maak een mengsel van de ingrediënten en leg dit in wit deeg.

Opmerking: "ghefrobolleert" betekent wellicht: gekookt (en ontbeend).

f. 4v-5 - Saus voor wildbraad - "Om venesoen hussepot - Roost bruin broot ende werket in asijl ende vessop ende steket door ende doet er wel vesch laert in ende brune boter, peper poer, not poer, nag hel poer, ende suicker ende laurier blaers, maer het venesoen moet ghesoden sijn met veel laert".

Ingrediënten: Wildbraad - bruin brood - azijn - hysop - vers spek - boter gemalen peper - muskaatnoot - kruidnagelpoeder - laurier - suiker.

Bereiding: Bereid het gebraad met veel spek. Rooster bruin brood en week het in azijn en hysop. Wrijf het door een zeef en voeg er bruine boter, gemalen peper, dito muskaatnoot, kruidnagelpoeder, laurier en suiker aan toe.

f. 5 - Saus voor gans - "Om sauce tot ghansen - Siet wittebroot met zoetemelck stampt een lettel roosmarijn ende tijmes met dat broot ende steket door met asijl ende ghynebeer poer".

Ingrediënten: geroosterd wittebrood - zoete melk - rozemarijn - tijm - azijn - gemberpoeder.

Bereiding: Kook het geroosterde wittebrood in zoete melk. Voeg er rozemarijn, tijm, azijn en gemberpoeder aan toe en wrijf het door een zeef.

f. 5 - Schapen- of lamsbout - "Om een ghespronghen jegot - Snijt laert vingheren lanck en dicke wendet ende keeret wel peper ende lardeeret daer mede ende siedet dan".

Ingrediënten: schapen- of lamsbout - lardeerspek.

Bereiding: Snij lardeerspek een vinger lang en een vinger dik. Draai het rond de bout en peper deze. Braad de bout.

Opmerking: "gesauteerd" betekent duidelijk gebraden in een pan; in dit geval zal "sieden" dus wel braden betekenen. In meerdere Gentse teksten komt de uitdrukking "ghespronghen jegot" of dus gesauteerde gigot of bout voor.

f. 5 - Saus voor eend - "Om sauce van intvoghels - Roost rogghen broot, legghet te weecke in asijn ende steket door doeter bruin boter in noten ende naghel poer neempt zoete appels ende anieyn smoort se al tsamen".

Ingrediënten: geroosterd roggebrood - azijn - boter - muskaatnoot - kruidnagelpoeder - zoete appelen - ui.

Bereiding: Leg het geroosterde brood te weken in azijn en wrijf het door een zeef. Voeg er bruine boter, muskaatnoot, kruidnagelpoeder, zoete appelen en 
uien aan toe en laat dit smoren.

f. 5 - Saus voor braadvarken - "Om sauce van braetveerckens - Siet wittebroot ende wijn met tornesol steket door met suicker ende caneele poer ende laetet tsamen sien".

Ingrediënten: wittebrood - wijn - "tornesol" - suiker - kaneelpoeder.

Bereiding: Breng de wijn met het wittebrood en de "tornesol" aan de kook. Wrijf het door een zeef en voeg er de suiker en het kaneelpoeder aan toe en laat het verder koken.

Opmerking: "tornesol", zie f. 3v-4 - Vinken.

f. 5 - Gesmoorde kapoen - "Om een capoen te smooren - Neempt lymoenen in sticken ghesneden wat sop vanden capoen wijn boter suicker ende foielle".

Ingrediënten: een gebraden kapoen - limoenen - wijn - boter - suiker - foelie.

Bereiding: De vloeistof voor het smoren maak je met braadvocht van de kapoen, in stukken gesneden limoenen, wijn, boter, suiker en foelie.

f. 5 - Gestoofde koevoet - "Om eenen coevoet te stoven - Neemt wijn boter, suicker ende chorinthen ofte den anders neempt groen cruict veriuis ende ende (sic) boter ofte neempt soffraen ghynebeere wat asijl ende boter".

Ingrediënten: koevoet - wijn - boter - suiker - krenten - groene kruiden verjuis - boter - saffraan - gember - azijn.

Bereiding: Stoof de koevoet of -poot met de andere ingrediënten.

f. 5v - Gele saus - "Om gelue sause - Neempt witte broot, asijn soffraen ende ghijnebeere".

Ingrediënten: wit brood - azijn - saffraan - gember.

Bereiding: Meng de vermelde ingrediënten.

f. $5 v$ - Saus voor snip - "De sauce van een sneppe - Neempt wijn boter suicker ende caneele ende leght rosteyen van wittebroot onder de sneppen".

Ingrediënten: wijn - boter - suiker - kaneel - geroosterd wittebrood.

Bereiding: Bereid de saus met de ingrediënten en leg de snip op geroosterd wittebrood.

f. 5v - Gestoofde karper - "Om eenen caerpel te stoven - Neempt wijn ende waetere anieyn ende laurierblaers roosmarijn ende boter peper ende naghel poer suicker ende lijfkoecke, gheweect in asijn ende die caerpel in sticke ghesneden".

Ingrediënten: karper - wijn - water - ui - laurierblaren - rozemarijn - boter

- peper - kruidnagelpoeder - suiker - peperkoek - azijn. 
Bereiding: Week de karper in azijn en laat hem stoven met de ingrediënten.

f. 5v - Gesmoorde schapen- of lamsbout - "Om een gigot te smooren - Siedet wel murwe al soudet moeten binden om dat van een niet vallen en soude, ende alst wel ghesoden es doeter laurier rosmarijn ghynebeer met stecken ghesneden ende gheelle foielle stellet te smooren met lanck sop, snijtter lymoenen in wat noten ende wijn al waers een pinte ende laetet een heure stoven ende dienet met lanck sop".

Ingrediënten: schapen- of lamsbout - laurier - rozemarijn - gember - foelie - limoenen - noten - wijn.

Bereiding: Bind de bout desnoods samen op te voorkomen dat hij bij het braden uiteenvalt. Laat hem als hij goed zacht is nog een uur smoren in veel vloeistof met laurier, rozemarijn, in stukken gesneden gember, gehele foelie, gesneden limoenen, noten en zowat $57 \mathrm{cl}$ wijn. Dien op met het kooknat aangelengd met water.

f. $5 v$ - Varkensribbetjes - "Om coteletten te smooren - Neempt stickens baeckevlees daer de swaerde af es ende daer wat bienkens an sijn, stickens van twee breet ende daer niet veel vlees an en es, snijt daer in lange kerten een vingher lanck siedet wel murwe ende latet dan versijpen, droochactich sijn, legghet up den rooster ende bradet dat roos sij smoordt dan anieyn met ronde schenen ghesneden int vesch sop wel murwe ende leghter dan de brayen in, doet daer in laurier, rosmarijn, greijne noten, ghynebeer poer ende veel rooden wijn suicker ende boter".

Ingrediënten: ontzwoerde varkensribbetjes - laurier - rozemarijn - greijne noten (?) - gember poeder - veel rode wijn - suiker - boter.

Bereiding: Neem stukken ontzwoerde varkensribbetjes waar nog botjes aan zijn, namelijk stukken van twee (? - mogelijk twee handsbreedten) breed waar niet veel vlees aan zit. Snij daarin lange sneden van zowat een vinger lang. Kook het zacht en laat het uitdruipen. Als het droog is, leg je het op de rooster en braad het tot het roze ziet. Smoor dan in schijven gesneden ui in het kookvocht en leg er het braadsel in, met toevoeging van de specerijen, veel rode wijn, suiker en boter.

f. 5v-6 - Kriekentaart - "Om criecke taerten - De custen moeten een weynich up staen, leghter in criecken daer de steenen uut ghedaen sijn, wel veele doet er in boter, suicker ende caneele poeder, deck se ende laetse backen".

Ingrediënten: ontpitte krieken - boter - suiker - kaneelpoeder.

Bereiding: Zorg ervoor dat de korst van het deeg een opstaande rand vertoont. Leg er veel ontpitte krieken in met boter, suiker en kaneelpoeder. Dek af en laat de taart bakken.

f. 6 - Kerveltaart - "Om kervel taerten - Capt kervel wel cleene, raspt daer over caes doeter in room van zoete melck of bij faulte zoete melck vijf ofte zes eyeren ghijnebeer poer ende peper ende minghelt onder een ende legghet int deech doeter in boter ende backse". 
Ingrediënten: kervel - geraspte kaas - room van zoete melk of 5 à 6 eieren gemberpoeder - peper - deeg - boter.

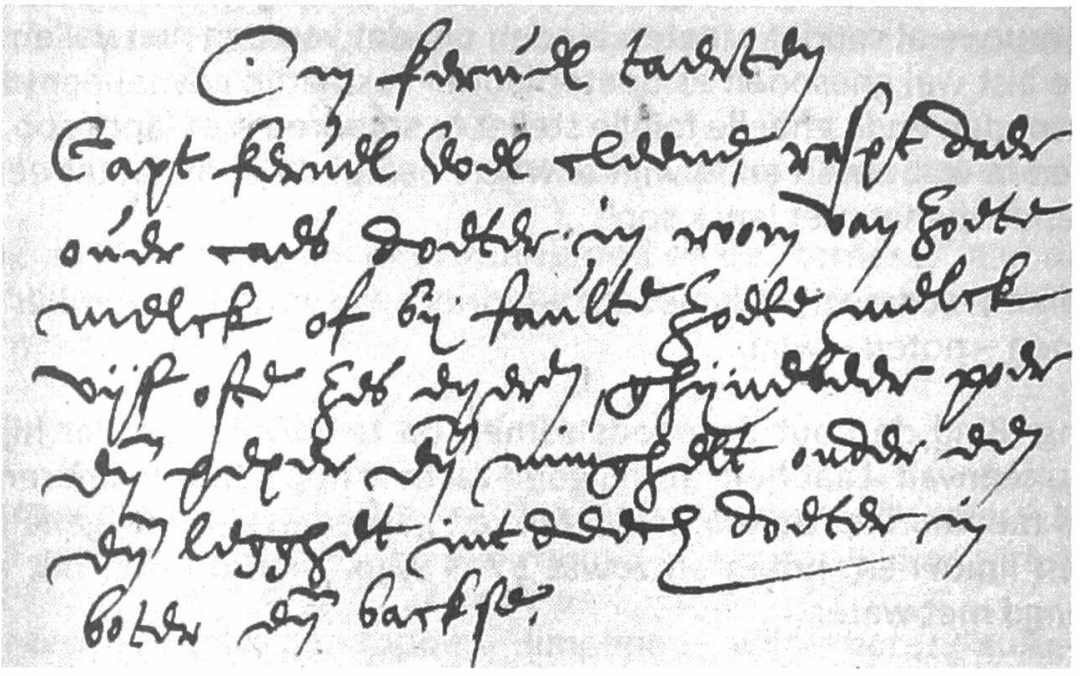

Kerveltaart

Bereiding: Rasp kaas over de fijn gehakte kervel en meng dit met de room, gemberpoeder en peper. Bij gebrek aan room kunnen er ook 5 à 6 eieren worden gebruikt. Leg dit mengsel in deeg met klontjes boter en bak de taart.

f. 6 - Wrongeltaart - "Om vrongel taerten - Minghelt in de vronghelen room ende twee ofte drij eijeren".

Ingrediënten: wrongel - room - eieren.

Bereiding: Vermeng de wrongel met room en 2 of 3 eieren.

f. 6 - Lombardische taart - "Om taerten ronbars - Neempt tot een pinte zoetemelck drij ofte vier lepelen blomme vijf ofte zes eyeren suicker ende soffraen maer die melck moet sieden eermen de blomme indoet met die eyeren stroijter caneele ende boter up".

Ingrediënten: $57 \mathrm{cl}$ zoete melk - bloem - eieren - suiker - saffraan - boter.

Bereiding: Breng de melk aan de kook en voeg er 3 à 4 lepels bloem, 5 of 6 eieren en suiker aan toe. Strooi er kaneel en boter op.

Opmerking: de interpretatie "ronbars" als Lombardisch werd ingegeven door de samenstelling van het recept zelf. Vergelijk met f. $4 \mathrm{v}$ - Lombardisch ei. Nochtans staat in een ouder handschrift een recept voor Lombardische taart op basis van in water gekookte snoek, varkensribben en kapoen. (20)

f. 6 - Stukken - "Om sticken ende andere manieren van brootwerck - Neempt tot twee eijeren twee lepels roosewaetere om eenen twalevaert coliandre ende blomme dattet redelick dicke es ende maecter af deech in wat maniere ofte faetzoene dat ghij wilt doeter wat suicker in".

Ingrediënten: 2 eieren - 2 lepels rozenwater - een weinig koriander (eigenlijk "om een twalevaert", dat is voor $1 / 2$ denier groot) - voldoende bloem om een 
vrij stevig deeg te bekomen.

Bereiding: Stukken of andere vormen van brood. Maak een vrij stevig deeg, voeg er wat suiker aan toe en maak er vormen mee naar believen.

f. 6 - Uier - "Om een helder te smooren - Neempt wijn, corinthen ende boter wat ghynebeer poer ende suicker den helder in schellen ghesneden ende tsamen ghesmoort".

Ingrediënten: uier - wijn - krenten - boter - gemberpoeder - suiker.

Bereiding: Smoor de aan schijven gesneden uier in wijn, krenten, boter, een weinig gemberpoeder en suiker.

f. 6 - Gestoofde kalfsbroodjes - "Om coteletten te maecken - Capt calfvlees wel cleene met wat versch speck ende groene cruiden doeter in ghijnebeer poer ende maeckse van de groote van een eij ende dan stoefse met veersch sop ende doeter in veriuis soffraen foielle ende wat noten".

Ingrediënten: kalfsgehakt met vers spek - groene kruiden - gemberpoeder verjuis - saffraan - foelie - muskaatnoot.

Bereiding: Meng het kalfsgehakt met vers spek, groene kruiden en gemberpoeder. Maak vormpjes van de grootte van een ei en stoof die in een vers bereide kooknat met verjuis, saffraan, foelie en muskaatnoot.

f. 6v - Gestoofde karper - "Om een caerpel te stoven - Neempt eenen caerpel ende spletten ende leghse soo in een pot, ende doeter in een pinte en alf rynschen wijn een croeseken goeden asijl ende zes ofte zeven laurierblaers, ende fruict wat anieuijn in boter, doeter in wat saut ende wel ghedect laetet stoven tot dat ghenoech es ghesoden es ende dan suldij noch wat asijl daer in doen foielle, ghynebeer peper soffraen letter laetet zo wat stoven, ende leght rosteijen in u pateel met suicker ende caneele, ghietet weij caerpel daer up".

Ingrediënten: een karper - 0,865 I rijnwijn - goede azijn - 6 of 7 laurierblaren - ui - boter - zout - foelie - gember - peper - saffraan - suiker - kaneel.

Bereiding: Splijt de karper en leg hem in een pot. Voeg er de rijnwijn, een kroesje goede azijn, de laurierblaren, in boter gefruite ui en zout aan toe en laat dit wel gedekt stoven tot het gaar is. Voeg er dan een weinig foelie, gember, peper en saffraan aan toe en laat nog wat verder stoven. Leg geroosterd brood op een schotel met suiker en kaneel en schik de karper daarop.

f. 6v - Uierpastei - "Om een pasteye van helder - Capt den helder wel cleen met veel scapen roet ende maerc ende ghynebeer peper ende suicker ende legghet zoo int deech".

Ingrediënten: uier - schapenvet - merg - gember - peper - suiker.

Bereiding: Hak de uier fijn. Voeg er schapenvet, merg, gember, peper en suiker aan toe en leg dit in deeg.

f. 6v - Gestoofde snoek - "Om eenen snoeck te stoven - Neempt den snoeck 
ende snijtten in sticken ende sieten alf ende doeter in veriuis ghynebeer boter ende cappers".

Ingrediënten: een snoek - verjuis - gember - boter - kappers.

Bereiding: Snij de snoek aan stukken en kook hem half. Voeg er dan verjuis, gember, boter en kappers aan toe.

f. 6v-Karpersoep - "Om een caerpel soppe te maecken - Capt het inghewant wel cleen met groen cruit ende drie ofte vier anieunen neempt water met een letter wijn, note poer naghel poer ende bruin boter, doet dit al te samen int voorseijde water, maer het moet langhe sien dan weect u zoppe ende als tander ghesoden es ghietet up de zoppe".

Ingrediënten: ingewanden van karper - groene kruiden - 3 of 4 uien - water - een weinig wijn - nootmuskaat - kruidnagelpoeder - bruine boter.

Bereiding: Kook alles lang in water. Week intussen brood en giet het kooksel erover.

f. $6 v$ - Oublies - "Pour faire des oublijes - Prenez de la farine de frument et passez la par un drap bien delije avecq un peu deau de rose un peu de suicker et de gengenbre avec le [ia]une d'un oeuf oultre prenez canelle en lieu de gengenbre mais peut".

Omtaling: Pour faire des oublies - Prenez de la farine de froment et déliezle avec un peu d'eau de rose, un peu de sucre et de gingembre et un jaune d'œuf. Passez le tout par un drap.Vous pouvez prendre de la cannelle en lieu du gingembre mais en petite quantité.

Ingrediënten: tarwebloem - rozenwater - suiker - gember - eigeel - eventueel kaneel.

Bereiding: Zeef de bloem door een doek en meng ze met rozenwater, suiker, gember en eigeel. In de plaats van gember kan men ook kaneel gebruiken, maar niet te veel.

Commentaar: De oublies werden in een soort wafeltjesijzer gebakken.

f. 6v-7 - Palinggalantine voor tijdens de vasten - "Om te maecken galentijne in de vastenen -Om zes ofte acht brocken soo neempt twee ofte drije palynghen ende ghij moet de graeten uut doen ende binden in malcanderen ende snijtse naer u goetdyncken ende ghij moetse te viere doen in roon wijn ende asijl van elcx eenen stoop ende sout ende roosmarijn ende laurier blaers ende als dat ghesoden es soo leght de sticken te drooghen ende neempt zes sneen gheroost broot ende leght dat te weecke int zelve zop ende steeckse deur een stamijne, neempt caneele een alf once een seseijn ghynebeer ende ooc galyngaen ende wit suicker".

Ingrediënten: 2 of 9 palingen - rode wijn - azijn - zout - rozemarijn en laurierbladeren - geroosterd brood - 13,5 g kaneel - 6,75 g gember - galanga en witte suiker 
Bereiding: voor zes tot acht stukken - Neem twee of drie palingen, ontdoe ze van de graten en bind ze samen. Snij ze dan in stukken en breng ze aan de kook in rode wijn en azijn, 2,3 I van elk, met zout, rozemarijn en laurier. Leg de stukken te drogen. Leg zes sneden geroosterd brood te week in het kookvocht en steek het door een roerzeef. Voeg er de specerijen en de suiker aan toe.

Opmerking: "galyngaen" of galangawortel, ook Thaise gember genoemd.

f. 7 - Sneeuw - "Om snee te maecken - Neempt drij lepels room half seur daer toe wat roosewater, een vierendeel soetemelck een alven dach te vooren ghemolken een luttel zuicker ende het witte van zes eyeren dat al te saemen doen in eenen grooten pot dan nemen een beercken roe ende altijt slaen van onder up ende alst wel schuimpt scheppet af ende legghet up rosteij ende met corinthen suicker ende caneele".

Ingrediënten: halfzure room - rozenwater - zoete melk die een halve dag voordien gemolken werd - een weinig suiker -6 eiwitten - geroosterd brood - krenten - suiker - kaneel.

Bereiding: Breng 3 lepels halfzure room, rozenwater, 14,5 cl zoete melk, suiker en eiwitten in een grote pot en klop dit men een berken garde van onder op tot het goed schuimt. Schep het op geroosterd brood met krenten, suiker en kaneel.

f. 7-7v - Marsepein - "Pour faire marcepain - II fault prendre ung demij livre de suickre ung cartron damandels et le fault peler et les bien estamper qui sont meues aprez fault prendre ledit suickre et le boulier avecq ungne culiere de leaue de rose tant quil ne fille plus, après fault prendre lesdits amandels et les boulier par ensamble tant quil soit espesse assez pour en faire patte, apres fault prendre un papier blan bien couvert de suickre qui soit aussij delij comme fleur de farine apres fault bien estre abile pour etendre le patte ainsij grande que vous le voulez avoir apres pour les secker il fault prendre le couvertoijer de ungne paille a tourte et mettre de cendre saude mais il fault bien garder de la brusler quant elle commence à seccer, il fault prendre une fille pour le defaire du papier apres le fault laisser seccer tant quil soit sec assez apres fault prendre le blan dung demij oeuf et le estricker avec ungne plume aprez le fault encore laisser secker mais il fault bien prendre garde quelle ne devienne roesse".

Omtaling: Pour faire du massepain - Prenez une demi livre de sucre et un quarteron d'amandes qu'il faut peler et bien piler pour les rendre molles. Bouillez le sucre avec une cuillerée d'eau de rose jusqu'à ce qu'il ne file plus. Ajoutez les amandes et bouillez-les dans le sirop jusqu'à ce que se soit assez épais pour en faire une pâte. Prenez un papier blanc bien couvert de sucre qui soit aussi délié que de la farine. Alors il faut être habile pour étendre la pâte aussi grande que vous le voulez. Pour la sécher, il faut prendre le couvercle d'une poêle à tourte et y mettre de la cendre chaude, mais en se gardant bien de ne pas la brûler quant elle commence à sécher. Il faut prendre un fil pour enlever le massepain du papier et encore le laisser sécher. Prenez ensuite un demi blanc d'œuf et badigeonnez en le massepain au moyen d'une plume. Laissez-le encore sécher, tout en prenant bien garde qu'il ne roussisse pas. 
Ingrediënten: 217 g suiker - 111 g gepelde en fijn gestampte amandelen rozenwater - eiwit.

Bereiding: Verwarm de suiker met een lepel rozenwater tot er geen draden meer worden gevormd. Voeg er dan de amandelen aan toe en laat verder koken tot er zich een pasta vormt. Spreid deze uit om een met suiker bestrooid wit papier, zoals dat ook met bloem gebeurt. Spreid dan de pasta open zo groot als je wil en bedek ze met het deksel van een taartvorm gevuld met hete as. Zo zal de pasta drogen, maar ze mag niet aanbranden. Maak ze dan met een draad los van het papier en laat ze verder drogen naar wens. Bestrijk de marsepein met een half eiwit. Gebruik hiertoe een vogelveer. Laat verder drogen, maar zonder dat het ros gaat kleuren.

Opmerking: "cartron" - een kwart pond, in het Frans "quarteron". Een "paille" is "une payelle", een pan.

f. $7 v$ - Spreten - "Pour faire des spretes - Prenez ung pot de laict dou et le trempes avec la fleur fort espesse apres il fault mectre sur le feu et le laisser siccer qui soit pres sec assez apres ij metterez deux ou trois oeufs pour ramolier et le fault bien toillier apres ij mettre encore trois ou quatre oeufs et le fault bien batre tout par ensamble aprez le pouvez tordre en trois livres de bure qui a este clarifié et qui nat esté salle et le fault laisser bouilier en ladite bure tant qui soyent rouge".

Omtaling: Pour faire des "spretes" - Prenez un pot de lait doux et mélangez-y de la farine assez épaisse. Mettez le mélange sur le feu et laissez sécher. Ajou56 tez deux ou trois œufs pour ramollir la pâte en touillez la énergiquement. Mettez y encore trois ou quatre œufs et battez bien. Tordez la pâte et faites frire dans trois livres de beurre clarifié non-salé jusqu'à ce que les spretes soient bien roussis.

Ingrediënten: zoete melk - bloem - eieren - 1,23 kg ongezouten boter.

Bereiding: Meng 1,15 I melk met dikke bloem en laat dit op het vuur uitdrogen. Voeg er twee of drie eieren aan toe om het zacht te maken en kneed dit goed. Voeg er nog eens drie of vier eieren bij en klop nog eens op. Bak de "spreten" dan in de gesmolten boter tot ze mooi gekleurd zijn.

Opmerking: het woord spreten kan verwant zijn met spriet, dit is een al dan niet aan het uiteinde gespleten stang(etje).

f. $7 v$-Deegsels - "Om te maecken dechsels - Neemt een pinte melck ende drij ofte vier eijeren ende wat blomme ende roeret al over een ende gietet up eenen ijseren lepel die gheheel es in de gheclarifieerde boter ende laetet zoo backen ghelijck die spenten".

Ingrediënten: 0,57 I melk - 3 of 4 eieren - een weinig bloem - geklaarde boter.

Bereiding: Meng alles dooreen. Schep ervan in een ijzeren lepel en laat dit fruiten in geklaarde boter, zoals "spenten "(?).

Opmerking: het gaat om een soort smoutebollen. 
f. 7v-8 - Gekonfijte kersen - "Pour confijer de cerijses - Prenez ung pot de leaue et ij adjoutant ung peu du ieu de ceryses et deulxs livres de suickre et le laissez boulier tout ensamble et bien escume et quant la sijrope et bien boulij ij fault mettre quatre livres de cerijses après que la cyrope soit ung peu refroidije afin que les cerijses ne ce fendent, aprez le bouilez tout par ensamble tant qui soient assez".

Omtaling: Pour confire des cerises - Ajoutez à un pot d'eau un peu du jus de cerise et deux livres de sucre. Faites bouillir et écumant bien. Lorsque le sirop sera bien bouilli, vous y mettrez quatre livres de cerises. II faut toutefois que le sirop soit un peu refroidi afin que les cerises ne se fendent pas. Après bouillez tout jusqu'à ce que ce soit assez.

Ingrediënten: 1,734 kg aalbessen - 867 g suiker - 1,15 I water - een weinig kersensap.

Bereiding: Breng de suiker, het water en het kersensap aan de kook tot het een dikke stroop wordt. Laat die een tijdlang rusten opdat de kersen niet zouden barsten. Voeg er de kersen aan toe en laat dit verder koken tot het voldoende ingedikt is.

f. 8 - Aalbessenmoes - "Om jenijver moes te maecken - Men moet de jenyvers door een seve duwen seer stijf ende neempt het sop ende doeter suicker in naer $u$ discretie ende laetet tsaemen sieden maer het moet wel gheschuimpt sijn, het moet sien tot dat es ghelijck ialeije".

Ingrediënten: aalbessen - suiker.

Bereiding : Duw de aalbessen op krachtige wijze door een zeef. Meng suiker naar discretie onder het sap en laat dit koken, maar schuim het nu en dan. Het moet eruit zien als gelei.

f. 8 - Gekonfijte aalbessen - "Om jenijvers te confijten - Tot twee pont ienyvers een pont en alf suicker ende een pinte water met wat zop daer inne om de zyrope te maecken gelijck om die criecken ende laet de zyrope wat verslaen heer ghij de ienijvers in doet, zij moet oock langhe sien tot sij dicke es".

Ingrediënten: $867 \mathrm{~g}$ aalbessen - $650 \mathrm{~g}$ suiker - $57 \mathrm{cl}$ water - een weinig aalbessensap.

Bereiding: Breng de suiker, het water en het aalbessensap aan de kook tot het een dikke stroop wordt, net als bij krieken. Laat ze een tijdlang rusten en voeg er de aalbessen aan toe.

f. 8 - Gekonfijte damaspruimen - "Pour confier prunes de Dama - II fault prendre $L X$ prunes et le mettre dedans ung four qui ne soit que un peu saut affin que vous prunes ne soijent trop molles et apres fault prendre un demij pinte de jeu du prunes et ung demij deaue claire et livre et demij du bon suickre et fault bouilier par ensamble tant qui soit syrope, et hotterez lors du feu, et quant il est froidt vous fault prendre vous prunes et les mettre dedans ladite syrope et metterez le tout sur le feu tant qui soit assez confijct".

Omtaling: Mettez 60 prunes dans un four tiède afin que vos prunes ne soi- 
ent pas trop molles. Prenez alors une demi pinte de jus de prune, une demi pinte d'eau claire et une livre et demie de bon sucre. Faites bouillir ensemble jusqu'à que se forme le sirop. Otez-le du feu et laissez refroidir. Ajoutez les prunes dans le sirop et remettez sur le feu jusqu'à ce qu'elles soient suffisamment confites.

Ingrediënten: 60 pruimen - 28,8 cl pruimensap - 28,8 cl klaar water - $650 \mathrm{~g}$ suiker.

Bereiding: Zet de pruimen in een lauwe oven om ze iets steviger te maken. Kook het pruimensap, het water en de suiker tot stroop. Laat die afkoelen en voeg er dan de pruimen aan toe. Plaats dit op het vuur tot de pruimen voldoende gekonfijt zijn.

Opmerking: damas(t)pruimen, "Prunus domestica", een nu vrijwel verdwenen langwerpige pruimensoort.

f. $8 v$ - Snoek of karper in pastei - "Om eenen snoeck ofte caerpel int deech te legghen ende de graete murwe te maecken - Men zallen snavonts te vooren inden asijl legghen ende tsanderdaechs int deech legghen ende gheel vollen met boter ende legghen lijmoenen up den visch ende over ghieten met bruine sauce ende doeter veel levende water in om die graete murwe te maecken ende als die pasteije een heure in den hoven ghestaen heeft neemptse uute ende ghietse vol veriuis ende dan weder inden hoven setten dien dacht ende nacht".

58 Ingrediënten: snoek of karper - azijn - deeg - boter - limoenen - bruine saus - regen- of bronwater - verjuis.

Bereiding: Leg de vis de avond te voren in azijn om de graten zacht te maken. Leg hem dan in deeg, vul hem op met boter, leg er limoenen op, overgiet met bruine saus en veel water. Als de pastei een uur in de oven heeft gestaan, overgiet je de vis met verjuis en plaats hem voor de rest van de dag en de volgende nacht terug in de oven.

Opmerking: Met "levende water" wordt regen- of bronwater bedoeld. Een recept voor bruine saus kom voor in KANTL, hs. 15 . Het luidt als volgt: 'Voor een bruine saus. Gemaakt van brood, daarin wordt kaneel, gember en peper gedaan, en gezeefd met wijn en een beetje azijn als het is gekookt'. (21)

f. $8 v$ - Karperpastei - "Om een caerpel pasteije - Ghij moet die graete van den caerpel gheel uut doen ende wel cleen cappen ende peper ende naghel poer indoen ende pessen wel ende dan moet ghij eenen palynck het vel afstroopen ende snijtten gelyck laert, ende laerdeert den voorseijden caerpel daer mede ende leghten dan int deech".

Ingrediënten: karper - peper - kruidnagelpoeder - paling - deeg.

Bereiding: Verwijder de graten uit de karper en hak het vlees klein. Pers het vocht eruit en bestrooi met peper en kruidnagelpoeder. Stroop een paling er lardeer daarmee de karper. Leg vervolgens in deeg.

f. $8 v$ - Damastwater - "Om te maken damast water - Neempt van alle wel 
rieckende blommen ende cruiden ende ghelas wijns ende een ghelas roosewater ende naghel poer, caneel poer ende laetet eenen nacht weecken al tsamen, maer het moet zeer nauwe ghestopt zijn".

Ingrediënten: allerlei welriekende bloemen en kruiden - een glas wijn - een glas rozenwater - kruidnagelpoeder - kaneelpoeder.

Bereiding: Laat alles gedurende een nacht trekken, maar zorg ervoor dat het volkomen afgesloten is.

f. 8v-9 - Godenaak - "Om te maecken godenaec - Neempt vijf pinten zop van queen ende vijf pont suickers ende datte al tsamen laeten zien tot dat claer es ende dan moet ghij nemen vier pond queen die ghesoden ende zeer ghestampt sijn ende doetse in de zyrope als sij wat versleghen es, ende laetet zoo zien tot dat dicke genoech es, maer men moet altijts roeren dat niet en berne".

Ingrediënten: 2,8 I sap van kwee - 2,1675 kg suiker - 1,734 kg fijngestampte gestoofde kweeën.

Bereiding: Kook het sap van kweeën en de suiker tot het helder wordt en laat dit enige tijd rusten. Voeg aan die stroop de fijngestampte gestoofde kweeën toe en breng dit opnieuw aan de kook tot het voldoende indikt, maar wel onder voortdurend roeren opdat het niet aanbrandt.

f. 9 - Biscuit - "Pour faire du bisquict - II fault ung livre du suickre ung livre de fleur XVI iaunes doeuf ungne petite cuiliere de gi, il fault batre les oeufs appart puis mettre le suicker et la fleur petit a petit dedans les oeuf et le bater tant quil soit bouilij".

Omtaling: Pour faire du biscuit - Prenez une livre de sucre, une livre de farine, 16 jaunes d'œuf et une petite cuillère de levure. Battez les œufs et ajoutez-y petit à petit le sucre et la farine. Battez ce mélange jusqu'à ce qu'il soit bouilli.

Ingrediënten: 433 g suiker - evenveel bloem - 16 eierdooiers - een lepeltje gist.

Bereiding: Eerst de eierdooiers afzonderlijk kloppen, dan de suiker en de bloem er beetje bij beetje toevoegen en blijven kloppen tot het kookt.

f. 9 - Suikerdeeg - "Pour faire patte de suickre - II fault prendre ungne demije cuilliere de gomme dragante puis tamise de suickre pour faire vostre patte".

Omtaling: Pour faire de la pâte à sucre - $\|$ faut prendre une demie cuillerée de gomme adragante. Puis tamisez le sucre pour faire votre pâte.

Ingrediënten: suiker - tragacantgom.

Bereiding: Maak het deeg met anderhalve lepel tragacantgom die onder de gezeefde suiker wordt gemengd.

Opmerking: tragacantgom is een slijmachtige gom van plantaardige oorsprong die onder meer in de suikerbakkerij diende als bindmiddel. 
Handgeschreven kookboeken in het Nederlands zijn uiterst zeldzaam, maar dit is al helemaal het geval met manuscripten die uitsluitend aan bakkerijproducten gewijd zijn. In het Gentse Stadsarchief (De Zwarte Doos, Gent) bleef er een bewaard in het Fonds Maertens de Noordhout nr. 839. Dit merkwaardige 18de-eeuwse document bevat 40 recepten van een aantal zoetigheden die ook nu nog tot het (Gentse) culinaire repertorium behoren.

De recepten werden genoteerd in een gepagineerd boekje van $11 \mathrm{~cm}$ breed bij $17 \mathrm{~cm}$ hoog. De eerste vier pagina's, waaronder de voorkaft, bevatten een lijst van weerbare mannen, eerder een soort burgerwacht, uit Stekene. De compagnie telde een kapitein, twee luitenanten, een vaandrig, een adjudant, een sergeant, een alferis, een drietal korporaals en een hele reeks soldaten. Eén van hen was Petrus Pastelerom, wiens naam inderdaad verwijst naar Stekene als Petrus Pastelerom (1677-1724) en Petrus Pastelerom (1706-1769). Vergelijking van de namenlijst met de begrafenisboeken van Stekene (22) liet niet toe nader te bepalen wanneer het boekje werd verder gebruikt om er de recepten in te noteren. Het is overigens niet zeker dat het boekje zich toen nog in Stekene bevond. Er zijn verder aanwijzingen in het taalgebruik dat de schrijver een Gentenaar was. Er moet dan ook worden volstaan door te stellen dat de recepten dateren van de tweede helft of misschien eerder van het laatste kwart van de 18de eeuw en dat de identiteit van de auteur niet kan worden vastgesteld.

Bij de meeste recepten wordt de (verkoop)prijs per pond vermeld. Dit is dit productieprijs, wat erop wijst dat de schrijver van het boekje professioneel bezig was als (suiker)bakker. Het bedrag is uitgedrukt in stuiver, dit is een twintigste van een gulden. De naamgeving van het gebak kan soms verwarrend zijn. Een (totaal) andere bereiding met dezelfde naam wordt soms elders op grond van lokale tradities en van commerciële overwegingen als streekprodukt geclaimd.

\section{Gentse bakkerijrecepten}

In deze uitgave vindt men een tekstuele weergave van de recepten, telkens gevolgd door de nodige ingrediënten, de aanwijzingen voor de bereiding in hedendaags Nederlands, de prijs en eventueel opmerkingen. De recepten werden alfabetisch gerangschikt, met vermelding van de pagina in het bakkerijboekje. Voor de omrekening van maten en gewichten dient te worden beklemtoond dat in Stekene dezelfde waarden golden als in Gent.

Hier en daar vindt men vergelijkbare recepten in het overzicht van recepten uit Nederlandstalige gedrukte kookboeken van 1500 tot 1800 van Marleen Willebrands (www.kookhistorie.nl).

\section{Wat vindt men in het bakkerijboekje?}

\begin{tabular}{|l|l|}
\hline amandelbrood (en speculaas) & makaron \\
\hline amandelen (gebrande -) & marsepein \\
\hline
\end{tabular}




\begin{tabular}{|l|l|}
\hline amandeltaart & mastellen \\
\hline assenkoekjes & mokken \\
\hline biscuit (lange - van Brussel) & oranjeschillen (gekonfijte -) \\
\hline biscuit met anijs & pain a la grecque \\
\hline boterkoeken & plat suiker \\
\hline broodgewicht & ringetjes en nootjes \\
\hline Brusselse mastellen & roggebrood \\
\hline citroenbiscuit & rotjes biscuit \\
\hline citroenbiscuit glaceren & schramoeliekens \\
\hline cuskens biscuit & speculaas (en amandelbrood) \\
\hline Frans brood & suikerkoeken \\
\hline Gentse vaste koeken & suikerpinnen \\
\hline heiligmaker & suikerstokken \\
\hline Hollands gebak & sukadekoek \\
\hline karamellen & tarwebrood \\
\hline knapkoek & wegskens \\
\hline koekenbak & wijnbollen \\
\hline krakelingen & zoetekoek \\
\hline krentenkoeken & \\
\hline
\end{tabular}

Amandelbrood (en speculaas) - p. 15 - "Amandel broot (ende speculatie) Een pond en alf zoete amandels niet gepeld een dobbel maetien melk en een dobbel maetien olie een vierd en laf botter t'saemen laeten kokken een alf vierde potten dry pond van bruynste suyker en ses pond groffe blom, als den deeg gemaekt is doet gy de amandels daer in en met een cap oft scheirsmes cappen tot dat sy cleyn genoeg zyn op een gesmeirde plaete. Speculatie het selve uytgenomen geen amandels en dat het suycker mag wit syn. Cost 8 stuyvers".

Ingrediënten: $650 \mathrm{~g}$ ongepelde zoete amandelen - $20 \mathrm{cl}$ melk - $20 \mathrm{cl}$ olie - 150 $\mathrm{g}$ boter $-1 / 2$ vierde potten of potas, bakpoeder dus $-1,3 \mathrm{~kg}$ donkerbruine suiker $-2,5 \mathrm{~kg}$ grove bloem.

Bereiding: Deeg maken met bloem, donkerbruine suiker, gesmolten mengsel van melk, olie en boter, en verder bakpoeder. Voor amandelbrood hakt men de amandelen fijn met een hak- of scheermes en voegt ze toe aan het deeg. Voor speculaas voegt men geen amandelen toe en mag men witte suiker gebruiken. Het deeg wordt gebakken op een ingevette plaat.

Prijs: 8 stuiver.

Opmerking: "potten" - er werd wellicht potas bedoeld. Voor de ontbijtkoek gebruikte men dit zwarte rijsmiddel dat in een Keulse pot en vooral onder water diende bewaard te worden. Potas is kaliumcarbonaat, een voedings- 
additief, dat op heden E501 wordt genoemd. Het is een onderdeel van bakpoeder en zorgt ervoor dat het deeg rijst. Het is niet duidelijk of hierbij een gewoon pond of een apothekerspond werd gebruikt. Veel doet het er niet toe omdat men nu toch een commercieel rijsmiddel zal gebruiken. Daarom wordt er geopteerd voor de term bakpoeder.

Amandeltaart - p. 29 - "Amandel taerten - een alf pond botter en soete amandels gestamt met een vierde brood suyker en dan neemt gy een alf pond van dit en doet daer in drey eyers en twee witten, en dat een alve ure lanck te saemen geslegen dan weynig witte brood en zitteroen in gerespt-de costen syn van tvolgende een pond blom omslaegen met waeter vast van deeg en dan een pond of wat min botter door gerold heeten oven".

Ingrediënten: $200 \mathrm{~g}$ boter - $200 \mathrm{~g}$ zoete amandelen - $108 \mathrm{~g}$ (geraspte of gemalen) broodsuiker -2 eieren -2 eiwitten - geraspte citroen.

Bereiding: Meng de boter met de amandelen en de suiker die vooraf samen werden gestampt. Neem hiervan $217 \mathrm{~g}$ en voeg daaraan drie eieren, twee eiwitten, een weinig wittebrood en geraspte citroen toe. Sla dit gedurende een half uur. Voor de "costen", wellicht de korst, kneed je 433 g bloem met water tot een vast deeg en rol je daardoor zowat $200 \mathrm{~g}$ boter. De oven moet heet zijn.

Opmerking: Suiker werd verkocht in de vorm van spits toelopende ronde broden. Voor keukengebruik werden ze geraspt of vermalen.

62 Assenkoekjes - p. 33 - "Assche koekxkens - een vierde blom omslaegen met waeter redelyk vast van deeg, daer dan door gerold veel gestampten caneel met een vierde botter sy wegen in deeg drey lood de twee dan gerold op het fatsoen van suyker koeken men stroeyt er op fyn gemaelen brood suyker gemingeld met blomme, daer moeten veel ollekens in gesteken worden om dat sy niet souden op trekken - op een plaete gebakken".

Ingrediënten: $110 \mathrm{~g}$ bloem - veel fijn gestampte kaneel - $100 \mathrm{~g}$ boter - fijn gemalen broodsuiker vermengd met bloem.

Bereiding: Meng de bloem met water tot een vrij vast deeg. Rol er de kaneel met de boter doorheen. Rol telkens twee partjes van $40 \mathrm{~g}$ uit zoals bij de bereiding van suikerkoeken (zie aldaar). Bestrooi met het mengsel van suiker en bloem. Frequent doorprikken om te voorkomen dat het deeg zou trekken. Op een plaat bakken.

Opmerking: Met Assekoek bedoelt men nu een specialiteit van de stad Asse, naar verluidt een uitvinding van Jan Baptist Lahoese in 1704 en daarmee zogezegd het oudste koekje van Vlaanderen. (23)

Biscuit met anijs - p. 7 - "viertien stuyvers het pond - Anys bosschuyt - een alf pond en een alf vierde eyers drey vierde en alf blom drey vierde en alf fyn gemaelen fyn gemaelen brood suyker hier moet men het gebruyken als in den cuskens bosquit hier vooren maer men doet er in een ons en alf anys saet en men doet het deeg ook in een blikken panne die gesmeirt is met botter in den oven als het brood uyt komt als het is gebakken doet met het uyt de panne en sanderdaegs sneyd men hem en droogd hem in den oven den deeg moet 
Ingrediënten: 4 eieren - $380 \mathrm{~g}$ bloem - $380 \mathrm{~g}$ fijn gemalen broodsuiker - $40 \mathrm{~g}$ anijszaad.

Bereiding: Gebruik de ingrediënten zoals in de bereiding van "cuskens bosquit" (zie aldaar), maar voeg er anijszaad aan toe. Leg het deeg in een met boter ingesmeerde blikken pan. Plaats dit in de oven als het brood eruit komt. Licht het uit de pan als het gebakken is. 's Anderendaags wordt het gebak gesneden, bestoven met broodsuiker en verder gedroogd in de oven.

Prijs: 14 stuiver per pond.

Boterkoeken - p. 32 - "Botter koeken weegt vier ofte vyf lood voor een oortien - Een pond en alf blomme een ey drey onsen gist met melk omslaegen redelyk vast dan daer door gerold een alf pond botter op en plaete gebakken".

Ingrediënten: $650 \mathrm{~g}$ bloem - 1 ei $-200 \mathrm{~g}$ boter $-80 \mathrm{~g}$ gist, opgelost in melk.

Bereiding: Maak een vrij vast deeg, rol er de boter doorheen en bak op een plaat.

Prijs: een boterkoek van 4 of 5 lood kost een oortje, dit is $1 / 2$ stuiver.

Broodgewicht - p. 40 - "terwen brood van 6 stuyver wegen 4 pond en 3 onsen gebakken - Brooden a 4-3 min een alf vierdeel - Roggen brooden van 8 stuyvers weegen 11 poond min een vierendeel gebaken - fyn brood van 2 stuyvers weegen gebakken 1 pond en 3 onsen".

Broodgewicht: Een tarwebrood van 6 stuiver weegt 1,815 kg gebakken - een brood van 4 stuiver weegt $1,245 \mathrm{~kg}$ - een roggebrood van 8 stuiver weegt $4,66 \mathrm{~kg}$ gebakken - een fijn brood van 2 stuiver weegt $0,515 \mathrm{~kg}$ gebakken.

Citroenbiscuit - p. 9 - "Zitteroen bosschuyt 16 stuyvers - een alf pond bitter en een alf pond soete amandels gepeld en gedroogd gestamt met witten van eyers dan nog seer weynig spiritus ingedaen als gy het suyker in doet en nog soo veel suyker als dat er noodig is het moet heel vast syn, dan uyt gerolt plat dan met worms uyt gesteken en op spellewerk papier gelet en gebakken als er brood uyt is en deen oven niet te heet om rood of gecoleurd te syn sult gy weynig van de fynst verwe daer in doen en mengelen t'sal wel syn".

Ingrediënten: $215 \mathrm{~g}$ gepelde en gedroogde en dito zoete amandelen - eiwit - suiker - alcoholische drank - kleurmiddel, bijvoorbeeld met citroensmaak.

Bereiding: Meng de fijn gestampte amandelen, de eiwitten en een weinig alcoholische drank. Voeg er zoveel suiker aan toen tot het deeg zeer vast wordt. Voeg er een beetje extra kleurmiddel aan toe. Rol het deeg plat uit en steek daar koekjes uit met het behulp van vormpjes. Leg ze op kantwerkpapier. Bak ze in een oven nadat het brood eruit gehaald werd, maar niet te heet, en laat de koekjes rood of gekleurd bakken.'

Prijs: 16 stuiver. 
Opmerking: "spellewerk papier" - glad wit papier waarin met spelden een patroon werd geprikt voor het vervaardigen van kant; nu gebruikt men bakpapier. Met spiritus wordt een alcoholische drank bedoeld, mogelijk brandewijn of jenever.

Cuskens biscuit - p. 6 - "viertien stuyvers het pond - Cuskens bosschuyt oft bisquit - een pond blom een pond en een ons fyn gemaelen brood suyker dry vierde en alf eyers gemaekt als volgt de witten van eyers geslagen in een pot met een roe tot dat het styf is de dooren in een comme ingedaen, dan het suyker by dit witte gedaen en geroert, en daer naer de blom meyt weynig seffens doorgeroert de blikken commekens moet men smeiren met botter daer in geschept alf vol is genoeg die geset op een plaete en bestoven met brood suyker, en dan in den oven maer die mag het brood al wat uyt syn ten sy het brood te slegt waer gebakken steekt niet lanck in den oven".

Ingrediënten: $433 \mathrm{~g}$ bloem - $460 \mathrm{~g}$ fijn gemalen broodsuiker - 6 eieren - boter.

Bereiding: Klop het wit van de eieren met een garde stijf en roer er de suiker doorheen. Voeg er de eierdooiers aan toe en meng er de bloem beetje bij beetje door. Smeer blikken bakvormpjes in met boter en doe ze half vol deeg. Zet ze op een plaat en bestuif met broodsuiker. Bak ze in de oven waar het brood al een tijdje uitgehaald werd, tenzij als het brood onvoldoende gebakken was. Niet te lang in de oven laten.

Prijs: 14 stuiver per pond.

Frans brood - p. 14 - "een pint en alf melk 3 onsen botter 2 eyers een alf hand sout redelyk wel gist logt van deeg dit moet wel geslaegen worden en wel rysen eer gy het opwerkt wegt ordinair 20 lood voor eenen stuyver ook soo veel waeter als melk, als het opgewerkt is legt gy het tusschen ieder een douwe op lynwaet alsoo laeten rysen in den oven geleyt met een hand paelken op een ander den hoven moet wel heet syn en moet een ure min of meer in de oven steken uyt den oven moet gy het afcrabben dat er geen koste van onder ofte boven can gesien worden".

Ingrediënten: 1,73 I melk - 1,73 I water - $81 \mathrm{~g}$ boter - 2 eieren - $1 / 2$ handvol zout - vrij veel gist.

Bereiding: Het deeg moet licht zijn, stevig gekneed en goed gerezen vooraleer het wordt opgewerkt. Leg na het opwerken telkens een stuk op lijnwaad om te rijzen. Plaats het brood in de oven met een "hand paelken" (?) op elkaar. De oven moet goed heet zijn en het brood zit ongeveer een uur in de oven. Als het uit de oven wordt het brood onder en boven afgekrabd om de (donkere) korsten te verwijderen.

Prijs: gewoonlijk kost een brood van 270 g een stuiver.

Gebrande amandelen - p. 20 - "Gebrande amandels - dit syn soete en die moeten gepelt worden, nog soo veel brood suyker als amandels, te saemen laeten koken tot dat sy droog worden en dan wat gestampten caneel overgestroyt - cost 16 stuyvers het pond".

Ingrediënten: gepelde zoete amandelen - evenveel broodsuiker - fijn ge- 
stampte kaneel.

Bereiding: de amandelen met de suiker laten inkoken tot het mengsel droog wordt - bestrooien met kaneelpoeder.

Prijs: 16 stuiver per pond.

Gekonfijte oranjeschillen - p. 19 - "Gesuykerde oranie schellen - Een pond schellen die moeten geheel fyn gesneden worden en twee pond brood suyker te saemen laeten kokken en als het begint te gaen styven een weynig gestampte cruynagel in gedaen, maer soo sy gaet verstyven moet gy altyd roeren en anders ook somwylen om dat het niet aen en sou branden als sy droog syn is het gedaen. Noteer alles dat moet gesoden worden moet in een casserolle gedaen worden anders is het niet goed".

Ingrediënten: 433 g fijn gesneden oranjeschillen - 867 g broodsuiker - fijn gestampte kruidnagel.

Bereiding: Laat de fijn gesneden schillen met de suiker in een metalen kom inkoken. Als het mengsel begint op te stijven, voeg je er de kruidnagelpoeder aan toe. Blijven roeren om het aanbranden te voorkomen. Als het mengsel droog is, is het klaar.

Gentse vaste koeken - p. 20 - "Gendsche vaste koeken - twee eyers een pinte melk een alf pinte olie een vierde en laf (sic) botter wel gist logt van deeg gebakken op den vloer op t'fatsoen van mastellen - wegen naer advenant van den tyd".

Ingrediënten: 2 eieren - 0,57 I melk - 0,285 I olie - 150 g boter - vrij veel gist.

Bereiding: Maak een licht deeg en bak op de ovenvloer zoals mastellen.

Prijs: het gewicht is afhankelijk van de tijdsconjunctuur.

Glaceren van citroenbiscuit - p. 10 - "Om den zitteroen bosschuyt wit van boven te maeken, maer dit doet men als hy gebakken is en hy moet koud syn - witten van eyers en daer weynig seffens brood suyker in geroerd tot dat het wit is en dan over den bosschuyt gedaen met een penceelken geel maeger en wilt gy gekoleurd suyker daer op hebben dat moet gy nu daer op doen en alsoo in syn eygen laeten droogen - als hy wit is cost hy 16 stuyvers anders maer veertien stuyvers".

Ingrediënten: eiwit - (gemalen) broodsuiker.

Bereiding: Roer het broodsuiker doorheen het eiwit tot het mengsel wit wordt. Breng dit met een penseel lichtjes aan op het gebakken en afgekoelde biscuit. Strooi daar desgewenst gekleurde suiker op en laat het indrogen.

Prijs: geglaceerde citroenbiscuit kost 16 stuiver, anders maar 14 stuiver.

Heiligmaker - p. 21 - "Heylig maeker - soo veel gewigt van suyker als van oninck met weynig pottas gemaekt met tarwen blomme van boven op de hoeken een schelleken sieckaede en hier en daer een gesuykerd oranie schelle 
ook moet den deeg hel vast syn gebakken in een flouwen hoven".

Ingrediënten: tarwebloem - suiker - evenveel honing - bakpoeder.

Bereiding: Men maakt een zeer vast deeg. Op de hoeken legt men een sukadeschil en hier en daar een gesuikerde oranjeschil. Bakken in een licht verwarmde oven.

Opmerking: De naam van dit gebak werd verbasterd van "hijlikmaker", huwelijksmaker, in het Frans "gâteau d'entremetteur". Het werd vooral gebruikt in samenhang met verloving en huwelijk. (24)

Hollands gebak - p. 13 - "Olands geback - Een pond soete amandels gepeld en gedroogd, gestamt met dooren van eyers, en daer naer een alf pond brood suyker ingedaen daer moet men toe hebben een buyse daer van agter een cleyn gaetien in is dunder als een cleynen vinger van boven wyd dit word daer soo door gedauwt et ... daer maekt gy in figure van dat gy begeirt op een plaet geset die gesmeirt is met olie van olyve gebakken in een flouwen oven wilt gy er gecoleurd suyker op hebben doet het er op soo haest als het gemaekt is - prys viertien stuyver".

Ingrediënten: 0,433 kg zoete amandelen, gepeld en gedroogd - eierdooiers $217 \mathrm{~g}$ broodsuiker.

Bereiding: Meng de fijn gestampte amandelen met de eierdooiers. Voeg er de suiker aan toe. Pers het deeg doorheen een buisje dat bovenaan wijd is en onderaan een gaatje vertoont, kleiner dan een pinkvinger. Smeer een plaat in met olijfolie en spuit figuurtjes naar wens. Bakken in een lichtverwarmde oven. Strooi er eventueel meteen gekleurde suiker op.

Prijs: 14 stuiver.

Karamellen - p. 25 - "Keirmelle - brood suyker laeten weeken met regenwaeter, en dan gekokt en soo dikwils als het op komt een wit van een ey in gedaen met een weynig regen waeter dat t'saemen is geslegen, en geschuymt soo lanck als er schuym op komt en laeten koken tot dat het claer is, en als gy se gaet maeken moet het koken, tot dat het aen een pyp steel haert word dan gegoten op een fynen steen die gesmeird is met olie van olyve en gemaekt in vierkante brokken en dan in een pampier gedaen met devieler (?) 16 stuyvers".

Ingrediënten: broodsuiker - regenwater - wit van ei.

Bereiding: Los de suiker op in regenwater en laat dit koken. Telkens als het schuim opkomt, voeg je er een wit van ei aan toe dat geslagen is met wat regenwater. Telkens weer afschuimen tot het mengsel helder wordt. Laten inkoken tot het opstijft aan een pijpensteel. Uitgieten op een fijne steen die werd ingesmeerd met olijfolie. In vierkante blokjes versnijden en in papier wikkelen.

Prijs: 16 stuiver.

Opmerking: Spaanse zeep is een harde zeep gemaakt met olijfolie en soda. 
Knapkoek - p. 38 - "Cnapcoek - den deeg word gemaekt van sirope met groffe roggen blomme, en met een sift wat terwen gruys door gesift redelyk logt van deeg en tot een pot sirope gebruykt men twee loet spaensche zeep die moet er in geschreept syn en twee loot aluyn dit moet alles te saemen kokken potas al ordinair wegen ontrent vier loot voor een oortien hoe ouder hope beter den deeg en mag wel vast syn als gy se maekt doet er de sirope in tot dat het wel is".

Ingrediënten: 1,15 I stroop - grove roggebloem - tarwegruis - 27 g geraspte Spaanse zeep - $27 \mathrm{~g}$ aluin - bakpoeder.

Bereiding: Een licht deeg maken met grove roggebloem. Daarin wat tarwegruis zeven. De geraspte Spaanse zeep met het aluin en de potas samen laten koken. Voeg er stroop aan toe tot het deeg vast genoeg is. Maak dan koekjes van ongeveer $55 \mathrm{~g}$.

Prijs: 4 lood voor een oortje.

Koekenbak - p. 26 - "Kokken back 16 stuyvers - Ses vierde deelen brood suyker en vier witten van eyers te saemen laeten koken, als het gekokt is een vierde sigtelingen van gesuykerd oranie schellen in gedaen, een pond en alf soete amandels gestamt met waeter met het suyker door een gedaen gebakken op een plaet eerst pampier van communie brood daer den deeg op te midden een schelleken secaede, bestoven met brood suyker in eenen flouwen hoven gebakken".

Ingrediënten: $650 \mathrm{~g}$ broodsuiker - 4 eiwitten - $108 \mathrm{~g}$ zeefsel van gesuikerde oranjeschillen $-650 \mathrm{~g}$ zoete amandelen.

Bereiding: Kook het broodsuiker met de vier eiwitten. Voeg er het zeefsel van gesuikerde oranjeschillen aan toe. Meng dit met de zoete amandels die vooraf werden gestampt met water. Leg ouwelpapier op een plaat en breng daarop het mengsel aan met in het midden een sukadeschil. Bestuif het geheel met broodsuiker. Bak dit in een licht verwarmde oven.

Prijs: 16 stuiver.

Krakelingen - p. 39 - "Craeklingen wegen gelyk de weggen - redelyke fyne blomme een pot soete melck twaelf eyers drey vierde botter te saemen met wat raep olie gemaekt niet alte vast van deeg ollen in gedaen als sy syn uyt gerolt".

Ingrediënten: vrij fijne bloem - 1,15 I zoete melk - 12 eieren - $300 \mathrm{~g}$ boter raapolie.

Bereiding: Maak van de ingrediënten een niet te vast deeg. Rol dit uit en maak er gaten in. Krakelingen wegen evenveel als "weggen" (?).

Opmerking: Misschien wordt met weggen hetzelfde bedoeld als de "wegskens" op p. 18.

Krentenkoeken - p. 30 - "corente koeken - vyf alf pinten soete melk een pond corinten ses ofte acht eyers wat olie een dobbel maetien sirope oft soo veel 
suyker redelyke blomme wel gist, wegen in deeg twaelf of dertien lood de twee, ook wat botter als den deeg gemaekt is door een gewerkt".

Ingrediënten: 1,44 I melk - 433 g krenten -6 of 8 eieren - een scheut olie $20 \mathrm{cl}$ stroop of evenveel suiker - vrij veel bloem en dito gist - boter.

Bereiding: Bereid het deeg met de ingrediënten en werk daardoor wat boter.

Opmerking: Twee krentenkoeken wegen 162 tot $175 \mathrm{~g}$.

Lange biscuit van Brussel - p. 34 - "Langen bosschuyt genaemt Brusselschen acht stuyvers het pond ofte wel twee voor een oortien - een pot en alf pinte soete melk een alf pond botter een alf pond suyker negen eyers weynig olie drey vierde gist logt van deege met setse op een gesmeirde plaete de roten drey vingers van elkanderen sy wegen seven lood oft minder de twee naer advenante van dierte van tgraen".

Ingrediënten: 1,3 | zoete melk - $200 \mathrm{~g}$ boter $-217 \mathrm{~g}$ suiker - 9 eieren - een scheut olie $-3 / 4$ gist (wellicht $3 / 4$ ons of $20 \mathrm{~g}$ ).

Bereiding: Maak een luchtig deeg. Plaats dit deeg op een ingesmeerde plaat. De rijen blijven drie vinger van elkaar. Twee stuks wegen $95 \mathrm{~g}$ of minder.

Prijs: 8 stuiver per pond of twee stuks voor een oortje, naargelang de prijs van het graan.

Makaron - p. 8 - "Mankuron - drey vierendeelen amandels, maer wilt gy soeten mancuron hebben al soet, wilt gy bitteren hebben al bitter, maer ordinair word het gedaen van elk den helft oft wat meer soet - tot drey vierde amandels die gepelt syn moet gy gebruyken vyf witten van eyers om mede te stampen tot dat hy cleyn is alsdan nog soo veel brood suyker als amandel in geroert dan geset op spillenwerk papier gebakken in een flouwen oven als er brood uyt komt - viertien oft sestien stuyver het pond".

Ingrediënten: $325 \mathrm{~g}$ amandelen (voor zoete makaron gebruikt men enkel zoete amandelen, voor bittere makaron bittere amandelen, gewoonlijk iets meer zoete dan bittere amandelen) -5 eiwitten $-325 \mathrm{~g}$ broodsuiker.

Bereiding: Stamp de amandelen fijn samen met de eiwitten. Roer er de suiker doorheen. Plaats dit op kantpapier en bak in een zachte oven als het brood eruit komt.

Prijs: 14 of 16 stuiver per pond.

Marsepein - p. 27 - "Mossipyn 16 stuyvers - Twee pond soete amandels gestamt met witten van eyers - dan een pond brood suyker en een alf pond fyne blome door een geroert, dan gemaekt op figure van zitteroen bosschuyt, geleyd op communie brood dan op papier en op een plaete redelyk eeten oven, het moet wel uytgedroogd syn".

Ingrediënten: 867 g zoete amandelen - eiwitten - 433 g broodsuiker - 217 g fijne bloem. 
Bereiding: Stoot de amandelen fijn met de eiwitten en roer er de suiker en de bloem doorheen. Vormen zoals citroenbiscuit (zie aldaar). Leg dit op ouwelbrood en dan op papier op een plaat. Laat het goed uitdrogen in een vrij hete oven.

Prijs: 16 stuiver.

Mastellen - p. 37 - "Mastellen van gemeene blomme omslaegen met twee potten waeter een pot soete melk eenig anyssaet met eenig coleander saet dat gestamt is in gedaen eenige raep olie wat vet ofte botter een pinte sirope ofte wat minder redelyk wel gist want sy moeten wel rijsen steken omtrent drey quaertiers in den oven wegen soo 7 lood voor een oort".

Ingrediënten: gewone bloem - 1,15 I water - 0,57 I zoete melk - anijszaad korianderzaad - raapolie, vet of boter - 0,57 I stroop - vrij veel gist.

Bereiding: Stoot het anijs- en korianderzaad fijn en meng het onder het deeg. Goed laten rijzen. Ongeveer drie kwartier in de oven.

Prijs: ze wegen 94 gram en kosten een oord.

Mastellen (Brusselse) - p. 4 - "Brusselsse mastelleken - een pinte zoete melk een vierde en alf botter eenige raepolie twee eyers en gist met redelycke goede blom dit alsoo gemaekt maer niet te vast van deeg dan eenigen tyd laeten rysen en dan ingewerkt een vierde en alf bruyn suyker anyssaet en caneel gestamt wegen 6 loot de twee op een maeger gesmeirde plaete der op worden sy plat gemaekt om te rysen legt men se op het brood als het uyt den oven komt en als sy syn geresen doet men er hollekens in een dan steekt mense in den oven daer het brood uyt komt sonder te eten redelyk wel moeten sy droogen soe gedaen is het heel wel".

Ingrediënten: 0,57 I zoete melk - 300 g boter - een weinig raapolie - 2 eieren - gist - goede bloem - anijszaad - kaneel.

Bereiding: Maak het deeg niet te vast. Laat het enige tijd laten rijzen en werk er de boter en het gestampte anijszaad en kaneel in. Leg de mastellen op het brood als het uit de oven komt om ze te laten rijzen. Leg ze daarna op een mager gesmeerde plaat en maak er een gaatje in. Plaats ze in de oven als het brood eruit komt, maar zonder verdere verwarming. Ze moeten goed gedroogd worden.

Prijs: twee stuks wegen $81 \mathrm{~g}$.

Mokken - p. 36 - "Mocken 3 oft vier stuyvers - oninck en sirope te saemen gekokt met groffe terwen blom tot drey potten sirope oft oninck 2 lood aluyn en twee dito spaensche zeepe ook wat anys saet oft cerrewi saet en tot ses ponden deeg doet gy er in drey loot potasch den deeg redelyk vast, op een gesmeirde plaete moeten sy geset worden".

Ingrediënten: honing - stroop - grove tarwebloem - 27 g aluin - 27 g Spaanse zeep - een weinig anijs- of karweizaad - aan 2,6 kg deeg voegt men $40 \mathrm{~g}$ potas toe. 
Bereiding: Maak het deeg vrij vast. Plaats de mokken op een gesmeerde plaat. Prijs: 3 of 4 stuiver

Opmerking: broodsuiker was witte suiker die werd afgeschraapt en/of vermalen van een suikerbrood.

Pain à la Grecque - p. 5 - "7 ofte acht stuyvers het pond - Met peyn allegreq - een pinte zoete melk een alf pond botter 2 eyers raep olie niet te veel, gist naer advenante met redelycke goede blomme alsoo gemaekt laeten eenigen tyd rysen en dan door gewerkt dat het er can naer smaeken dan gemaekt in lange rollen ontrent twee vingers dik die geset op een plaete die maeger gesmeird is en dan een vinger van malkanderen een snee die gemaekt en set een rol dan dander dry vingers laeten rysen op het brood dat en gebacken sonder eeten backt seker een alve ure somwylen nog meer".

Ingrediënten: 0,57 I zoete melk - $200 \mathrm{~g}$ boter - 2 eieren - een weinig raapolie - de nodige gist - goede bloem.

Bereiding: Maak het deeg vrij vast en bewerk het goed. Maak rollen van twee vingers dik en plaats die op een mager gesmeerde plaat op een vingerdikte afstand van elkaar. Maak een insnijding en laat ze drie vinger rijzen op het brood dat pas gebakken is. Laat minstens een half uur laten bakken zonder de oven verder te verwarmen.

Prijs: 7 of 8 stuiver per pond.

$70 \quad$ Plat suiker - p. 17 - "Plat suyker cost viertien stuyvers - een onse gom dragom laeten weeken met roosen waeter en weynig spiritus in gedaen daer van gebruykt gy soeveel hair poyer als brood suyker en dat moet gy met weynig seffens daer in vrijven tot dat het geel hardt is - dan maekt gy het soo gy wilt en laeten droogen onder den oven daer mede ist gedaen".

Ingrediënten: $27 \mathrm{~g}$ tragacantgom - rozenwater - een weinig alcoholische drank - broodsuiker - haarpoeder.

Bereiding: Laat de tragacantgom in rozenwater weken en voeg er de alcoholische drank aan toe. Wrijf er het haarpoeder en de suiker beetje bij beetje doorheen tot het mengsel zeer hard wordt. Geef het dan vorm en laat het drogen onder de oven.

Prijs: 14 stuiver.

Opmerking: "dragom" - tragacantgom - een slijmachtige gom van plantaardige oorsprong die onder meer in de suikerbakkerij diende als bindmiddel. Vreemd is het gebruik van hair poyer of haarpoeder; de enige betekenis van dit woord betreft poeder dat voor het opmaken van het haar en de pruik werd gebruikt.

Ringetjes en nootjes - p. 11 - "Rincxkens - 10 eyers een vierde en alf bruyn suyker een alf quart caneel gestamt dit te saem gemaekt met goede blom heel vast van deeg en dan gemaekt dan moeten sy gesoden worden en uyt het sodende waeter scheppen en in coud waeter doen en dan gelyd op een lynen doek om wat op te droogen en daer naer gedroog in den oven als het 
brood uyt komt.Voor de nootjens het selve te doen gelyk boven maer wilt gy daer eenig zitteroen zaep in doen het is wel maer niet noodig - prys van die twee sorten negen stuyvers".

Ingrediënten: goede bloem - 10 eieren $-162 \mathrm{~g}$ bruine suiker $-54 \mathrm{~g}$ gestampte kaneel.

Bereiding: Met de ingrediënten een zeer vast deeg maken. Voer er naar wens enig citroensap aan toe. Geef de ringetjes of nootjes vorm en kook ze in water. Uitscheppen en in koud water leggen. Op een linnen doek laten drogen en verder laten drogen in de oven als het brood eruit komt.

Prijs: 9 stuiver voor de beide soorten.

Roggebrood - p. 35 - "Van ses ponden roggen meel kan men maeken negen ponden deeg en seven pond veertig looden brood soo dat alle roggen brood moet een alf vierde deel verdroogen noeyt minder maer wel meer, dit raekt veele het goed ofte slegt graen".

Bereiding: van 2,6 kg roggemeel maakt men 3,9 kg deeg en 3,574 kg brood. Roggebrood moet ten minste een achtste van zijn gewicht verliezen, afhankelijk van de kwaliteit van het graan.

Rotjes biscuit - p. 23 - "Rottiens bosschuyt 8 stuyvers - een pinte zoete melk 10 a 12 eyers een alf pond botter eenig suyker eenige olie wel gist goede blomme gemaekt in lange rollen wegen een alf pond gy moet se soo by malkanderen setten dat sy by een konen komen en aen een blyven soo gebakken de plaete gesmeird, als sy coud syn sanderdags gesneden en suyver overgevreven en gedroogd in den oven, daer moeten twee rollen by malkanderen syn".

Ingrediënten: 0,57 | zoete melk - 10 tot 12 eieren - 200 g boter - een weinig suiker - een weinig olie - vrij veel gist - goede bloem.

Bereiding: Maak van het deeg lange rollen van $217 \mathrm{~g}$ en wel zodanig dat ze elkaar raken. Bak ze op een gesmeerde plaat. Als ze's anderendaags afgekoeld zijn, wrijf je ze proper, snij ze en droog ze in de oven.

Prijs: 8 stuiver.

Schramoeliekens - p. 32 - "Schramoelikens vier ofte vyf lood voor een oortien een alf pint soete melk fyne blomme twee eyers weynig raep olie weynig suyker, gist naer advonante op een plaete gebakken".

Ingrediënten: 0,29 | zoete melk - fijne bloem - 2 eieren - een weinig raapolie - een weinig suiker - gist.

Bereiding: Bak het deeg op een plaat.

Prijs: 54 à $67 \mathrm{~g}$ voor een oortje.

Suikerkoeken - p. 12 - "Suyker koeken - een pint zoete melk een alf pond botter ses eyers en een weynig olie wel gist alsoo word den deeg gemaekt met goede blom weegen vier loot de twee als sy opgerolt syn dan plat uytgerolt dan sult gy se eens over het water stryken dat sy langs deen sey geel nat syn 
en gy legt se dan op het suyker dat moet syn soo volgt drey vierde wit suyker een vierd en alf blom wel door een gevreven en den doeck daer op geplakt en dan geset op een plaete die goed gesmeird is en op het brood laeten rysen en gebakken als het brood uyt komt".

Ingrediënten: goede bloem - 0,57 I zoete melk - $200 \mathrm{~g}$ boter - 6 eieren - een weinig olie - vrij veel gist - $325 \mathrm{~g}$ witte suiker - $162 \mathrm{~g}$ bloem.

Bereiding: Rol het deeg op en rol het daarna weer uit en maak het aan één kant nat met water. Leg het deeg op de suiker waar de bloem doorheen werd gewreven. Kleef daarop een doek en plaats dit op een goed gesmeerde plaat. Laat dit rijzen op het brood als het uit de oven komt. Bak hierna de koeken.

Twee stuks wegen $54 \mathrm{~g}$.

Suikerpinnen - p. 28 - "Suyker pinyn sestien stuyver - Broodsuyker laeten weeken met regen waeter en dan gekokt en als het op komt telkens een wit van een ey in gedaen dat met weynig regenwaeter geslegen is, en geschuymt, dan moet het koken tot dat het hard word aen een pyp steel, dan een weynig botter in gedaen, gegoten op een steen gesmeird met olie van olyve, dan getrokken tot dat het heel wit is en dan crullekens gemaekt".

Ingrediënten: broodsuiker - regenwater - eiwitten.

Bereiding: Los de suiker op in regenwater en laat dit koken. Voeg er telkens als het schuim opkomt een wit van ei aan toe dat geslagen is met wat re72 genwater. Telkens weer afschuimen tot het mengsel helder wordt. Dan laten inkoken tot het opstijft aan een pijpensteel. Voeg er een weinig boter aan toe en giet het mengsel uit op een met olijfolie ingesmeerde steen. Trek het mengsel tot het helemaal wit is en vorm er krulletjes van.

Prijs: 16 stuiver.

Suikerstokken - p. 16 - "Suyker stekken - Een weynig waeter en drey vierd bruyn suyker tsaemen laeten kokken tot dat het aen een pypsteel hardt word dan uytgegoten op eenen fynen steen die gesmeird is met olie van olyve, om wit te maeken moet gy se trekken, anders moet gy se soo lanck laeten liggen op dien steen tot dat gy se in uw anden cont verdragen dan gaet gy se maeken gy besigt in de plaets van blom styfsel en gy moet se haestig af snyden want soo sy hard syn is het te laet".

Ingrediënten: een weinig water - 325 g bruine suiker.

Bereiding: Laat het water en de suiker inkoken tot het opstijft aan een pijpensteel. Giet dit uit op een met olijfolie ingesmeerde steen. Om het mengsel wit te maken, moet het worden getrokken. Laat het zo lang liggen tot je het met de handen kan aanpakken. Geef de suikerstokken meteen vorm. Gebruik stijfsel in plaats van bloem en haast je om ze te snijden, want als ze hard zijn, is het te laat.

Sukadekoek - p. 21 - "Secaede koek - 3 vierde en alf voor seven stuyvers tot ses pond deeg van oninck en rogge blom een pond sickaede een pond sigtelingen van gesuykerd oranie schellen een alf ons gestamt cruynaegels te 
Ingrediënten: honing - roggebloem - 433,5 g sukade - evenveel zeefsel van gesuikerde oranjeschillen $-13,5$ g gestampte kruidnagel.

Bereiding: Maakt het deeg en leg sukade op de koek.

Prijs: 7 stuiver voor $380 \mathrm{~g}$.

Tarwebrood - p. 31 - "Tregard van terwen deeg van vier pond meel maekt gy ses pond deeg van ses pond deeg comt vyf pond en een vierde brood en is geel goed, noteert alle brood moet een alf vierde op een pond verdroogen witte brood bakt men van de fynste blomme met soete melk tot ider pont drey eyers en wat botter - den deeg redelyk vast en gist om wel te rysen".

Bereiding: Van 1,734 kg tarwemeel maakt men 2,7 kg deeg en 2,168 kg brood. Noteer wel dat alle brood een achtste van zijn gewicht moet verliezen. Wit brood bakt men van de fijnste bloem met zoete melk, 3 eieren en wat boter. Voeg voldoende gist toe om het vrij vaste deeg te laten rijzen.

Wegskens - p. 18 - "Wegskens als volgt - een pot melk een pond en alf corenten die moeten gespoelt syn een alf pond en een vierde botter twaelf eyers eenige raepolie redelyk wel gist alsoo moet den deeg gemaekt worden met goede blomme den deeg wat laeten rysen wegen 15 lood de twee redelyken heeten oven weynig voor sy in den oven gaen gesneden sy mogen niet lanck in den oven steken gebakken op den vloer".

Ingrediënten: goede bloem $-1,15$ I melk -650 g gespoelde krenten $-300 \mathrm{~g}$ boter - 12 eieren - een weinig raapolie - vrij veel gist.

Bereiding: Laat het deeg wat rijzen. Snij het vlak voor je het in de oven steekt. Bak ze niet te lange tijd op de ovenvloer.

Twee stuks wegen $202 \mathrm{~g}$.

Wijnbollen - p. 22 - "Wyn bollen acht stuyvers - een oortien en alf melk een dobbel maetien olie en een vierde en alf botter te saem laeten koken, de melk met een vierde en alf suyker, negen eyers, een alf quaert caneel wel gist alsoo gemaekt met goede blomme op een gesmeirde plaete op het brood laeten rysen en gebakken als er brood uyt den oven komt, gy moetse al rond maeken en een weynig van malkanderen setten op de plaete".

Ingrediënten: goede bloem - voor $1 \frac{1}{2}$ oortje melk - $20 \mathrm{cl}$ olie - $150 \mathrm{~g}$ boter $-162 \mathrm{~g}$ suiker -9 eieren $-54 \mathrm{~g}$ kaneel.

Bereiding: Laat de olie en de boter smelten en voeg er de andere ingrediënten aan toe. Maak ronde vormen van het deeg. Plaats ze op enige afstand vaneen op een ingesmeerde plaat en laat ze rijzen op het brood als het uit de oven komt. Bak dan de wijnbollen.

Prijs: 8 stuiver.

Zoetekoek - p. 24 - "Soete koek deeg van oninck die is heel goed oninck en 
sirope te saem is ook goed dit laeten koken en gemaekt van fyne roggen blom redelyk vast als gy hem gaet bakken gebruykt gy drey loot pottas tot 6 pond deeg de potasch moet wel van van malkaer gevreven syn dat er geen keykens in een syn om oranie coek doet gy maer de schellen in als hy is wit getrokken en wat gemengeld kruyd - word ordinair verkogt tegen vier stuyvers het pond den deeg word ook eer den koek in den oven gaet gestreken met waeter als hy er uyt komt met lym die gemengd is met waeter soo doet gy met alle diergelyke".

Ingrediënten: fijne roggebloem - honing en eventueel stroop - 13,5 g potas per $0,87 \mathrm{~kg}$ deeg.

Bereiding: Het beste resultaat is enkel met honing, maar honing met stroop is ook goed. Breng dit aan de kook en maak een vrij vast deeg met fijne roggebloem. De potas moet goed gewreven worden opdat er geen stukjes zouden inzitten. Het deeg wordt met water bestreken voor het in de oven gaat en nog eens met lijm vermengd met water als het eruit komt. Om oranjekoek te verkrijgen, voegt je er schillen en gemengde kruiden toe aan het deeg als het wit getrokken is.

Prijs: wordt verkocht voor 4 stuiver per pond.

\section{Noten}

1 Universiteit Gent, Bibliotheek, hs. 1035. Desen bouc leert wel ende edelike spijse te bereedene tetene werd uitgegeven door C.A. Serrure als Keuken boek, uitgegeven naar een handschrift der vijftiende eeuw, Maatschappij der Vlaemsche Bibliophilen, dl. 10, Gent, 1872. Men vindt een nieuwe uitgave op de website www.coquinaria.nl van Christianne Muusers.

2 Koninklijke Academie Voor Nederlandse Taal En Letterkunde (KANTL), hs. 15. Braekman, W.L. , Een belangrijke middelnederlandse bron voor Vorselmans' Nyeuwen Coock Boeck (1560), in: Volkskunde, dl. 87, 1986, nr. 1, p. 1-24; Braekman, W.L., Een nieuw zuidnederlands kookboek uit de vijftiende eeuw, in: Scripta: mediaeval and renaissance studies, dl. 17, Brussel, 1986. Zie ook: www.coquinaria.nl.

3 KANTL, hs. 476.

4 Dit boek met keukenrecepten en medische remedies voor mensen en dieren kan in digitale versie worden geraadpleegd in de webstek van de Erfgoedbibliotheek Hendrik Conscience in Antwerpen.

5 Een overzicht vindt men op http://www.magirus.net/2007/10/09/vlaamse-kookboeken1500-1800flemish-cookery-books-1500-1800libri-fiamminghi-di-cucina-1500-1800/ van Hilde Sels en op http://culinaryhistory.org.

6 Faipoult, G.C., Mémoire statistique du Departement de l'Escaut, met inleiding door Paul Deprez, in Oostvlaams Verbond van de Kringen voor Geschiedenis, Gent, 1960, p. 202.

7 Zie bv. Lievevrouw-Coopman, L., Oude Gentsche maten en gewichten, in Oost-Vlaamsche Zanten, 1946, jg. 21 nr. 12,2, p. 63-83.

8 Faipoult, ibidem.

9 http://www.goldeneggs.com.au/nutrition/what_is_an_egg.html

10 Rijksarchief Gent, Familiefonds, nr. 3064, Handboek van huishoudelijke uitgaven en keu- 
kenrecepten. De inventaris vermeldt dat het behoorde tot een verzameling archieven die door de erfgenamen van de graven d'Hane de Steenhuize werd geschonken.

11 Vander Meersch, P.C., Memorieboek der stad Ghent : van 't j. 1301 tot 1737, dl. 3, Gent, 1854, respectievelijk p. 126, 133, 134 en 144.

12 Du Mont, Recueil généalogique de familles originaires des Pays-Bas ou y établies, Rotterdam, 1775, p. 9;- De Vegiano, J.C.J., Suite du supplément au Nobiliaire des Pays-Bas et du comté de Bourgogne, dl. 3, 1630-1661, Malines, 1779 p. 53.

13 Met oprechte dank aan Gilbert De Leu en de equipe vrijwilligers in het Gentse Stadsarchief voor het verstrekken van deze informatie.

14 Stadsarchief Gent (SAG), reeks 330, Schepenboeken van Gedele, nr. 131, 1611-1612, f. 56v-57 - staat van goed goedgekeurd op 29 oktober 1611.

15 In SAG, reeks 332, Minuten van de boedelstaten voor schepenen van Gedele.

16 Zie www.kookhistorie.nl. Uitg. Schildermans, J., Sels, H. \& Willebrands, M., Lieve schat, wat vind je lekker? Het Koocboec van Antonius Magirus (1612) en de Italiaanse keuken van de renaissance, Leuven, 2007, ISBN 978905826 5005. Online te raadplegen onder http://www.magirus.net/wp-content/uploads_magirus/2007/09/magirus-1612-transcriptie.pdf.

17 Voor het recept voor viooltjespoeder, zie: Witgeest, S., Natuurlyk tover-boeck of Speeltoneel der konsten, Amsterdam, 1698, p. 458, recept 60.

18 Voor het recept voor damastwater, zie hierboven f.8v; voor een ander recept: Witgeest, S., p. 458-459, recept 62 .

19 De Vries, M., Woordenboek der Nederlandsche Taal, dl. 8, p. 943.

20 Universiteitsbibliotheek Gent, hs. 1035, Wel ende edelike spijse, hst. $1 \mathrm{nr} .10$, uitgave op website www.coquinaria.nl van Christianne Muusers.

21 KANTL, hs. 15, deel 2 nr. 49. Uitgave op website www.coquinaria.nl van Christianne Muu sers.

22 De Heemkring d'Euzie zette die online via www.deuzie.be.

23 www.ascania.be/asca-special-koek1.html

24 De Vries, J., Nederlands Etymologisch Woordenboek, Leiden, 1971. 